\title{
Análisis Macroscópico y Microscópico del Desarrollo Embrio- nario y Fetal en el Gato (Felis catus), en Relación con el Desarrollo de la Vesícula Coriónica y de la Placenta
}

\author{
Macroscopic and Microscopic Analysis of the Embryonic and Fetal Growth in the Cat (Felis \\ catus), in Relation to Chorionic Vesicle and Placental Development
}

Julio Illanes; Cupertina Orellana; Bárbara Fertilio; Víctor Leyton \& Felipe Venegas

\begin{abstract}
ILLANES, J.; ORELLANA, C.; FERTILIO, B.; LEYTON, V. \& VENEGAS, F. Análisis macroscópico y microscópico del desarrollo embrionario y fetal en el gato (Felis catus), en relación con el desarrollo de la vesícula coriónica y de la placenta. Int. J. Morphol., 25(3):467-481, 2007.
\end{abstract}

RESUMEN: La gata doméstica (Felis catus) presenta una gestación que dura, en promedio $62 \pm 5$ días. Sin embargo, establecer la edad gestacional en forma más o menos precisa resulta difícil, ya que no existe un análisis que correlacione el tamaño de la vesícula coriónica; desarrollo de la placenta; desarrollo embrionario y fetal durante la gestación. En este trabajo se utilizaron 12 úteros grávidos, provenientes de gatas mestizas entre 8 y 18 meses de edad, éstos fueron fijados en formol neutro al 10\%. Para cada útero se determinó el número de vesículas coriónicas, de cada una se removieron el embrión, feto y la placenta, los que fueron medidos, tarados y fotografiados para su análisis morfológico. Las etapas del desarrollo embrionario y fetal fueron establecidas conforme a las características y estructuras externas de los embriones y fetos, desde el inicio hasta el término de la gestación. A los 13 días de gestación se observó una gástrula tardía. Embriones somíticos, entre los 13 y 18 días. Embriones prefetales, entre los 18 y 28 días, y fetos desde el día 28 hasta el nacimiento. El amnios se cierra a los 17 días; la formación de la cara y cuello ocurre entre los 16 y 28 días, y de los miembros, entre los 17 y 28 días de gestación. A los 15 días de gestación comienza el latido cardiaco, momento en que se observa el tubo endocárdico. El tabicamiento del corazón se produce entre los 17 y 20 días. El tubo neural está cerrado a los 17 días de gestación. Todos los parámetros estudiados en los diferentes estadios del desarrollo en el gato están significativamente correlacionados $(\mathrm{p}<0.0001)$.

PALABRAS CLAVE: Gato; Felis catus; Embriología; Desarrollo embrionario; Desarrollo fetal.

\section{INTRODUCCIÓN}

El gato doméstico (Felis catus) proviene aparentemente, de la cruza del gato montés europeo (Felis silvestris) y del gato doméstico africano (Felis lybica) en Europa y Asia. Su domesticación habría comenzado en el antiguo Egipto, alrededor del año 2.000 A.C. Los romanos habrían introducido esta especie a Bretaña alrededor del año 300 D.C. Luego, serían los colonizadores europeos los encargados de introducir al gato doméstico en el resto del mundo (Serpell, 1988).

La gestación en la gata dura, en promedio, $62 \pm 5$ días, (Gruffydd-Jones, 1990; Melivilu, 1994 y Felmand \& Nelson, 1996). Para su diagnóstico se puede utilizar la palpación transabdominal, en forma óptima entre los días 20 a 30 postcoito, momento en que las vesículas coriónicas son identificables. Dentro de la imagenología, la radiología se puede emplear a partir de los 42 a 45 días. Un método más confiable para el diagnóstico de gestación y determinación de la edad gestacional es la ecografía. Su uso se recomienda a partir de los días 18 a 25 postcópula, cuando es posible detectar los primeros movimientos del corazón y la frecuencia cardiaca (Verstegen et al., 1993 y Melivilu). La ecografía permite además, determinar tamaño de la camada y la existencia de anormalidades de la preñez (England, 1998).

El presente estudio permite aportar mayor información a la existente, la que se puede emplear, por ejemplo, para la determinación de la edad gestacional en esta especie, al describir lo que sucede en las diferentes etapas del desarrollo embrionario y fetal, en relación con el desarrollo de la vesícula coriónica y de la placenta. 


\section{MATERIAL Y MÉTODO}

La edad gestacional, se determinó de acuerdo a la fecha probable de cruza registrada, la que fue corroborada mediante la fórmula propuesta por Nelson \& Cooper (1975).

Se seleccionaron y utilizaron 12 úteros grávidos con 4 a 5 vesículas coriónicas cada uno, provenientes de hembras felinas domésticas mestizas, de entre 8 y 18 meses de edad, obtenidos mediante ovariohisterectomía, la que se realizó bajo anestesia general con Ketamina ( $20 \mathrm{mg} / \mathrm{kg}$ ). Los úteros grávidos se fijaron en formol neutro al $10 \%$. Se determinaron el número de vesículas coriónicas, sus diámetros transversal y longitudinal, como también su perímetro transversal. A continuación, se procedió a la obtención de embriones, fetos y las placentas respectivas de cada vesícula coriónica. De cada vesícula coriónica, se registraron el perímetro transversal y diámetros transversal y longitudinal. Se consideraron además, los siguientes parámetros: peso y longitud cráneo-caudal para los embriones y fetos; peso, ancho y grosor para las placentas. El ancho de la placenta considera el segmento interhematoma marginal, en el lado mesometrial y el grosor se estableció en su zona media en un microscopio óptico (Olympus BX41 con cámara digital Olympus C-5060 Wide zoom, 5.1 mega píxel) con grilla cuadriculada ubicada en el ocular con aumento de $10 \mathrm{x}$.

Las vesículas coriónicas, embriones, fetos y placentas fueron fotografiados en un microscopio estereoscópico Leitz Wetzlar, para su posterior análisis macroscópico. Se realizó un análisis comparativo para determinar los diferentes estadios de desarrollo desde el inicio hasta el término de la gestación, de acuerdo a las características estructurales externas de los embriones y fetos. Para este análisis se comparó con el desarrollo descrito para otras especies (Tabla I).

Análisis estadístico: Los datos se analizaron a través de sus promedios y desviaciones estándar, expresados en la Tabla II; y la relación entre los parámetros estudiados se estableció mediante sus correlaciones y coeficientes de regresión, expresados en los Gráficos I, II y en la Tabla III.

Tabla I. Comparación de los distintos periodos del desarrollo embrionario y fetal en algunas especies de mamíferos y un reptil.

\begin{tabular}{ccccc}
\hline Presomítico & Somítico & Prefetal & Fetal & Especie \\
\hline $0-21$ días & $21-36$ días & $36-58$ días & $58-90$ días $(33.3 \%)$ & Octodon degus $(1)$ \\
$0-20$ días $\left(^{*}\right)$ & $20-58$ días $(*)$ & $0-21$ días & $21-72$ días $(38.5 \%)$ & Liolaemus tenuis t $(2$ y 3) \\
$(\text { estadio } 1 \text { al } 11)^{*}$ & $($ estadio 12 al 29)* & $($ estadio 30 al 36) & (estadio 37 al 43) & \\
$0-13$ días & $13-18$ días & $18-28$ días & $28-62$ días $(54.8 \%)$ & Felis catus \\
& $($ estadio 1 al 4) & $($ estadio 5 al 8$)$ & (estadio 9 al 12) & \\
$0-20$ días & $20-35$ días & $35-56$ días & $56-266$ días $(78.9 \%)$ & Homo sapiens (4) \\
\hline
\end{tabular}

(*) Los asteriscos indican que ambos periodos de desarrollo ocurren durante la permanencia del huevo "in útero" y los periodos prefetal y fetal ocurren posterior a la oviposición, ya que son individuos ovovivíparos. Por lo cual, el desarrollo total hasta la eclosión es de $58+72=130$ días, aproximadamente. 1. Rojas et al., 1982; 2. Lemus \& Duvauchelle, 1966; 3. Lemus et al., 1981; 4. Sadler, 2004.

\section{RESULTADOS}

Las características macroscópicas para cada estadio del desarrollo embrionario y fetal del gato, se muestran en las Figs. 1 a 12. Las características de la vesícula coriónica rodeada de su pared uterina, sin la pared uterina y abierta con el embrión o feto expuesto, para cada estadio, se muestran en las Figs. 13 a 24. El desarrollo macroscópico de la cara y cuello, se muestra en las Figs. 25 a 30. Las Figs. 31 a 45 , muestran cortes histológicos transversales en los primeros estadios de desarrollo del gato, donde se puede observar la diferenciación del sistema nervioso (neurulación), mesodermogénesis, cambio del esqueleto mesenquimático a cartilaginoso (vértebras), formación del corazón desde tubo endocardico hasta el tabicamiento de atrios y ventrículos. Diferenciación pulmonar desde etapa embrionaria hasta la etapa seudoglandular.
En la Tabla II, se muestran las variables consideradas en los diferentes estadios del desarrollo embrionario y fetal del gato (embrión/feto, vesícula coriónica y placenta). En la Tabla III y en los Gráficos I y II, se muestran los coeficientes de correlación lineal (r) entre las variables analizadas, del desarrollo embrionario y fetal del gato (Felis catus). En la Tabla I, se muestra el análisis comparativo del desarrollo embrionario y fetal del gato con el del degu, la lagartija ovovivípara y la especie humana.

Estadio 1. Gástrula tardía de 13 días de gestación: A nivel cefálico se observa la placa neural ensanchada. A nivel medio de este embrión plano, se observa el surco neural profundo y abierto en toda su extensión, inicio del proceso de neurulación. Se observan tres a cuatro pares de somitos bien definidos, inicio del proceso de mesodermogénesis. Ha comenzado la formación del amnios por plegamiento (plectamnios), observándose sus solevantamientos cefálico, 
Tabla II. Muestra los diferentes estadios (E), expresados en días (d) del desarrollo embrionario y fetal en el gato (Felis catus); el número de vesículas por estadio (n), el promedio y la desviación standard para las diferentes variables analizadas. Embrión: PF (peso fetal), LCC (longitud cráneocaudal). Vesícula coriónica: PT (perímetro transversal), DT (diámetro transversal) y DL (diámetro longitudinal). Placenta: PP (peso placenta), AP (ancho placenta) y GP (grosor placenta).

\begin{tabular}{|c|c|c|c|c|c|c|c|c|c|c|c|}
\hline \multirow[b]{2}{*}{$\mathbf{E}$} & \multirow[b]{2}{*}{ d } & \multirow{2}{*}{\multicolumn{2}{|c|}{$\mathbf{n}$}} & \multicolumn{2}{|c|}{ EMBRIÓN/FETO } & \multicolumn{3}{|c|}{ VESÍCULA CORIÓNICA } & \multicolumn{3}{|c|}{ PLACENTA } \\
\hline & & & & PF $\mathrm{g}$ & $\mathrm{LCC} \mathrm{cm}$ & PT cm & DT $\mathbf{c m}$ & DL cm & PP g & AP cm & GP cm \\
\hline 1 & 13 & 5 & $\begin{array}{l}\bar{X} \\
\delta\end{array}$ & $\begin{array}{c}\mathbf{0 . 0 0 1 4 6} \\
(0.0001673)\end{array}$ & $\begin{array}{l}\mathbf{0 . 3 3} * \\
(0.03)\end{array}$ & $\begin{array}{c}\mathbf{2 . 9 2} \\
(0.2949576)\end{array}$ & $\begin{array}{c}\mathbf{0 . 9} \\
(0.0612372)\end{array}$ & $\begin{array}{l}\mathbf{1 . 0 7} \\
(0.13)\end{array}$ & $\begin{array}{c}\mathbf{0 . 1 9 3 3 4} \\
(0.0002608)\end{array}$ & $\begin{array}{c}\mathbf{0 . 3 0 2} \\
(0.0044721)\end{array}$ & $\begin{array}{c}\mathbf{0 . 0 4 9} \\
(0.0007)\end{array}$ \\
\hline 2 & 15 & 4 & $\begin{array}{l}\bar{X} \\
\delta\end{array}$ & $\begin{array}{c}\mathbf{0 . 0 0 5 2} \\
(0.0002582)\end{array}$ & $\begin{array}{l}\mathbf{0 . 6 5 *} \\
(0.04)\end{array}$ & $\begin{array}{l}\mathbf{3 . 9 5} \\
(0.1)\end{array}$ & $\begin{array}{c}\mathbf{1 . 1 8} \\
(0.05)\end{array}$ & $\begin{array}{l}\mathbf{1 . 2 6} \\
(0.08)\end{array}$ & $\begin{array}{c}\mathbf{0 . 2 1 4 5} \\
(0.0002944)\end{array}$ & $\begin{array}{c}\mathbf{0 . 7 5} \\
(0.057735)\end{array}$ & $\begin{array}{c}\mathbf{0 . 0 5 0 3} \\
(0.0005)\end{array}$ \\
\hline $\mathbf{3}$ & 16 & 4 & $\begin{array}{l}\bar{X} \\
\delta\end{array}$ & $\begin{array}{l}\mathbf{0 . 0 0 7 4 5} \\
(0.0001)\end{array}$ & $\begin{array}{c}\mathbf{0 . 3 3 8} \\
(0.025)\end{array}$ & $\begin{array}{l}\mathbf{4 . 0 7 5} \\
(0.05)\end{array}$ & $\begin{array}{c}\mathbf{1 . 1 8} \\
(0.05)\end{array}$ & $\begin{array}{c}\mathbf{1 . 3} \\
(0.01)\end{array}$ & $\begin{array}{c}\mathbf{0 . 2 5 9} \\
(0.002)\end{array}$ & $\begin{array}{r}\mathbf{1 . 0 7 5} \\
(0.05)\end{array}$ & $\begin{array}{r}\mathbf{0 . 0 5 0 3} \\
(0.0005)\end{array}$ \\
\hline 4 & 17 & 4 & $\hat{x}$ & $\begin{array}{c}\mathbf{0 . 0 3 7 9} \\
(0.0008869)\end{array}$ & $\begin{array}{c}\mathbf{0 . 6 7 5} \\
(0.029)\end{array}$ & $\begin{array}{c}\mathbf{6 . 0 2 5} \\
(0.4716991)\end{array}$ & $\begin{array}{c}\mathbf{1 . 8 4} \\
(0.11)\end{array}$ & $\begin{array}{c}\mathbf{2 . 0 5} \\
(0.13)\end{array}$ & $\begin{array}{c}\mathbf{0 . 9 7 8 3} \\
(0.0007937)\end{array}$ & $\begin{array}{c}\mathbf{1 . 8 5} \\
(0.057735)\end{array}$ & $\begin{array}{c}\mathbf{0 . 0 7 7} \\
(0.0029)\end{array}$ \\
\hline 5 & 18 & 4 & $\underset{\delta}{\bar{X}}$ & $\begin{array}{c}\mathbf{0 . 1 1 2 3} \\
(0.0068095)\end{array}$ & $\begin{array}{c}\mathbf{0 . 8 2 5} \\
(0.029)\end{array}$ & $\begin{array}{c}\mathbf{7 . 1} \\
(0.2160247)\end{array}$ & $\begin{array}{c}\mathbf{2 . 2 3} \\
(0.13)\end{array}$ & $\begin{array}{c}\mathbf{2 . 8 3} \\
(0.15)\end{array}$ & $\begin{array}{c}2.2705 \\
(0.1649)\end{array}$ & $\begin{array}{l}\mathbf{2 . 4 7 5} \\
(0.05)\end{array}$ & $\begin{array}{l}\mathbf{0 . 1 0 7 5} \\
(0.002)\end{array}$ \\
\hline 6 & 19 & 4 & $\begin{array}{l}\bar{X} \\
\delta\end{array}$ & $\begin{array}{c}\mathbf{0 . 2 1 5 7 5} \\
(0.0173694)\end{array}$ & $\begin{array}{c}\mathbf{1 . 1} \\
(0.071)\end{array}$ & $\begin{array}{c}\mathbf{8 . 2 5} \\
(0.2081666)\end{array}$ & $\begin{array}{c}\mathbf{2 . 6 3} \\
(0.13)\end{array}$ & $\begin{array}{c}\mathbf{2 . 9 4} \\
(0.1108678)\end{array}$ & $\begin{array}{c}\mathbf{2 . 8 7 1 8} \\
(0.2922)\end{array}$ & $\begin{array}{c}\mathbf{2 . 6 5} \\
(0.057735)\end{array}$ & $\begin{array}{c}\mathbf{0 . 1 5} \\
(0.0082)\end{array}$ \\
\hline 7 & 20 & 5 & $\begin{array}{l}\bar{X} \\
\delta\end{array}$ & $\begin{array}{c}\mathbf{0 . 4 9 3 3} \\
(0.0115436)\end{array}$ & $\begin{array}{c}\mathbf{1 . 5} \\
(0.061)\end{array}$ & $\begin{array}{c}\mathbf{9 . 2 6} \\
(0.6107373)\end{array}$ & $\begin{array}{c}\mathbf{2 . 8 8} \\
(0.11)\end{array}$ & $\begin{array}{c}\mathbf{3 . 6} \\
(0.35)\end{array}$ & $\begin{array}{c}4.395 \\
(0.7491)\end{array}$ & $\begin{array}{c}\mathbf{2 . 8 6} \\
(0.0547723)\end{array}$ & $\begin{array}{c}\mathbf{0 . 1 6 9} \\
(0.0065)\end{array}$ \\
\hline 8 & 24 & 4 & $\underset{\delta}{\bar{x}}$ & $\begin{array}{c}1.32 \\
(0.0388)\end{array}$ & $\begin{array}{c}\mathbf{2 . 2 0 3} \\
(0.005)\end{array}$ & $\begin{array}{c}\mathbf{9 . 8 2 5} \\
(0.2362908)\end{array}$ & $\begin{array}{c}\mathbf{3 . 0 5} \\
(0.13)\end{array}$ & $\begin{array}{c}\mathbf{3 . 8} \\
(0.34)\end{array}$ & $\begin{array}{c}\mathbf{6 . 6 4 7} \\
(0.2289)\end{array}$ & $\begin{array}{c}\mathbf{3 . 2 5} \\
(0.057735)\end{array}$ & $\begin{array}{c}\mathbf{0 . 1 8 5} \\
(0.0001)\end{array}$ \\
\hline 9 & 28 & 4 & $\begin{array}{l}\bar{X} \\
\delta\end{array}$ & $\begin{array}{c}2.625 \\
(0.0957)\end{array}$ & $\begin{array}{c}\mathbf{3 . 2} \\
(0.082)\end{array}$ & $\begin{array}{c}\mathbf{1 0 . 9 5} \\
(1.3076697)\end{array}$ & $\begin{array}{c}\mathbf{3 . 6 5} \\
(0.52)\end{array}$ & $\begin{array}{c}\mathbf{5 . 1} \\
(0.38)\end{array}$ & $\begin{array}{l}\mathbf{1 0 . 2 2 5} \\
(0.943)\end{array}$ & $\begin{array}{l}3.75 \\
(0.1)\end{array}$ & $\begin{array}{l}\mathbf{0 . 2 1 7 5} \\
(0.005)\end{array}$ \\
\hline 10 & 34 & 4 & $\begin{array}{l}\bar{x} \\
\delta\end{array}$ & $\begin{array}{c}7.1625 \\
(0.1377)\end{array}$ & $\begin{array}{c}\mathbf{5} \\
(0.141)\end{array}$ & $\begin{array}{c}\mathbf{1 2 . 6} \\
(0.2708013)\end{array}$ & $\begin{array}{c}\mathbf{3 . 9 5} \\
(0.13)\end{array}$ & $\begin{array}{c}\mathbf{6 . 9 3} \\
(0.32)\end{array}$ & $\begin{array}{l}\mathbf{1 6 . 5 6 2 5} \\
(1.0531)\end{array}$ & $\begin{array}{r}\mathbf{4 . 0 7 5} \\
(0.05)\end{array}$ & $\begin{array}{l}\mathbf{0 . 3 2 7 5} \\
(0.005)\end{array}$ \\
\hline 11 & 40 & 4 & $\begin{array}{l}\bar{X} \\
\delta\end{array}$ & $\begin{array}{c}12.825 \\
(1.6978)\end{array}$ & $\begin{array}{c}\mathbf{6 . 1 8 3} \\
(0.131)\end{array}$ & $\begin{array}{c}14 \\
(0.8164966)\end{array}$ & $\begin{array}{c}\mathbf{4 . 4 0 7 5} \\
(0.1479583)\end{array}$ & $\begin{array}{c}\mathbf{8 . 3 5} \\
(0.1589549)\end{array}$ & $\begin{array}{c}18 \\
(0.5715)\end{array}$ & $\begin{array}{l}4.275 \\
(0.05)\end{array}$ & $\begin{array}{l}\mathbf{0 . 3 2 7 5} \\
(0.005)\end{array}$ \\
\hline 12 & 60 & 4 & $\begin{array}{l}\bar{x} \\
\delta\end{array}$ & $\begin{array}{c}\mathbf{1 1 6 . 1} \\
(3.948)\end{array}$ & $\begin{array}{l}\mathbf{1 2 . 9 7 5} \\
(0.33)\end{array}$ & $\begin{array}{c}17 \\
(0.05)\end{array}$ & $\begin{array}{c}\mathbf{5 . 3 3} \\
(0.05)\end{array}$ & $\begin{array}{c}\mathbf{1 1 . 2} \\
(0.28)\end{array}$ & $\begin{array}{c}21.1 \\
(1.8294)\end{array}$ & $\begin{array}{l}\mathbf{4 . 6 2 5} \\
(0.05)\end{array}$ & $\begin{array}{r}\mathbf{0 . 3 3 2 5} \\
(0.005)\end{array}$ \\
\hline
\end{tabular}

* La longitud cráneo-caudal para los estadios 1 y 2 corresponde a la longitud total, ya que son embriones planos.

caudal y lateral. Al corte histológico transversal, se observan el ectodermo, mesodermo y endodermo y se aprecia el surco neural y la notocorda. Figs. 1a, 1b, 1c, 13, 31, 32 y 33.

Estadio 2. Embrión somítico de 15 días de gestación y 18 pares de somitos: A nivel cefálico, se observa con claridad el proceso frontonasal, como también las placodas nasales en su región ínfero-nasal. Ubicadas más lateralmente, entre los procesos frontonasal y maxilar se observa la vesícula óptica, y detrás del segundo arco branquial, la vesícula ótica. A nivel faríngeo, se observan el primer y segundo arcos branquiales y el tercero en formación, además de la primera y segunda hendiduras branquiales. Hacia caudal, se observa en la cavidad pericárdica, el tubo endocárdico fusionado que, al corte histológico, muestra el endocardio, gelatina cardiaca y epimiocardio. También se puede observar el intestino anterior, medio y posterior. El tubo neural se está cerrando, observándose aún los neuroporos anterior y posterior. Bajo el tubo neural se aprecia la notocorda. El amnios está cerrado en un $50 \%$, permanece abierto desde los últimos siete pares de somitos hacia cefálico. Figs. 2a, $2 \mathrm{~b}, 2 \mathrm{c}, 14,34,35$ y 36 .
Estadio 3. Embrión somítico de 16 días de gestación y 26 pares de somitos: A nivel cefálico, se observan las vesículas encefálicas primitivas (prosencéfalo, mesencéfalo y romboencéfalo) y las curvaturas cefálica, cervical y pontina. El estomodeo, está delimitado cranealmente por el proceso frontonasal, lateralmente por los procesos maxilares y, caudalmente, por los procesos mandibulares. Se observa la vesícula ótica detrás de la segunda hendidura branquial; y entre los procesos frontonasal y maxilar se observa la vesícula óptica. A nivel faríngeo, se observan el primer, segundo y tercer arcos branquiales y el cuarto en formación, además de las primeras, segundas y terceras hendiduras branquiales. El primer par de arcos branquiales aún no se han fusionado en el plano mediano. Hacia caudal, se observa el tubo endocárdico incurvado dentro de la cavidad pericárdica. El embrión adquiere la forma de $\mathrm{C}$ y es totalmente tubular. El tubo neural está casi completamente cerrado. Se observa claramente el intestino anterior y comienza a cerrarse el intestino posterior, existe amplia comunicación del intestino medio con el saco vitelino. El amnios se ha cerrado completamente a nivel cefálico. Figs. 3a, 3b, 15, 25, 37, 38 y 39. 
ILLANES, J.; ORELLANA, C.; FERTILIO, B.; LEYTON, V. \& VENEGAS, F. Análisis macroscópico y microscópico del desarrollo embrionario y fetal en el gato (Felis catus), en relación con el desarrollo de la vesícula coriónica y de la placenta. Int. J. Morphol., 25(3):467-481, 2007.

Gráfico I. Correlación entre el diámetro transversal y longitudinal de la vesícula coriónica, longitud cráneocaudal, ancho y grosor de la placenta en Felis catus.

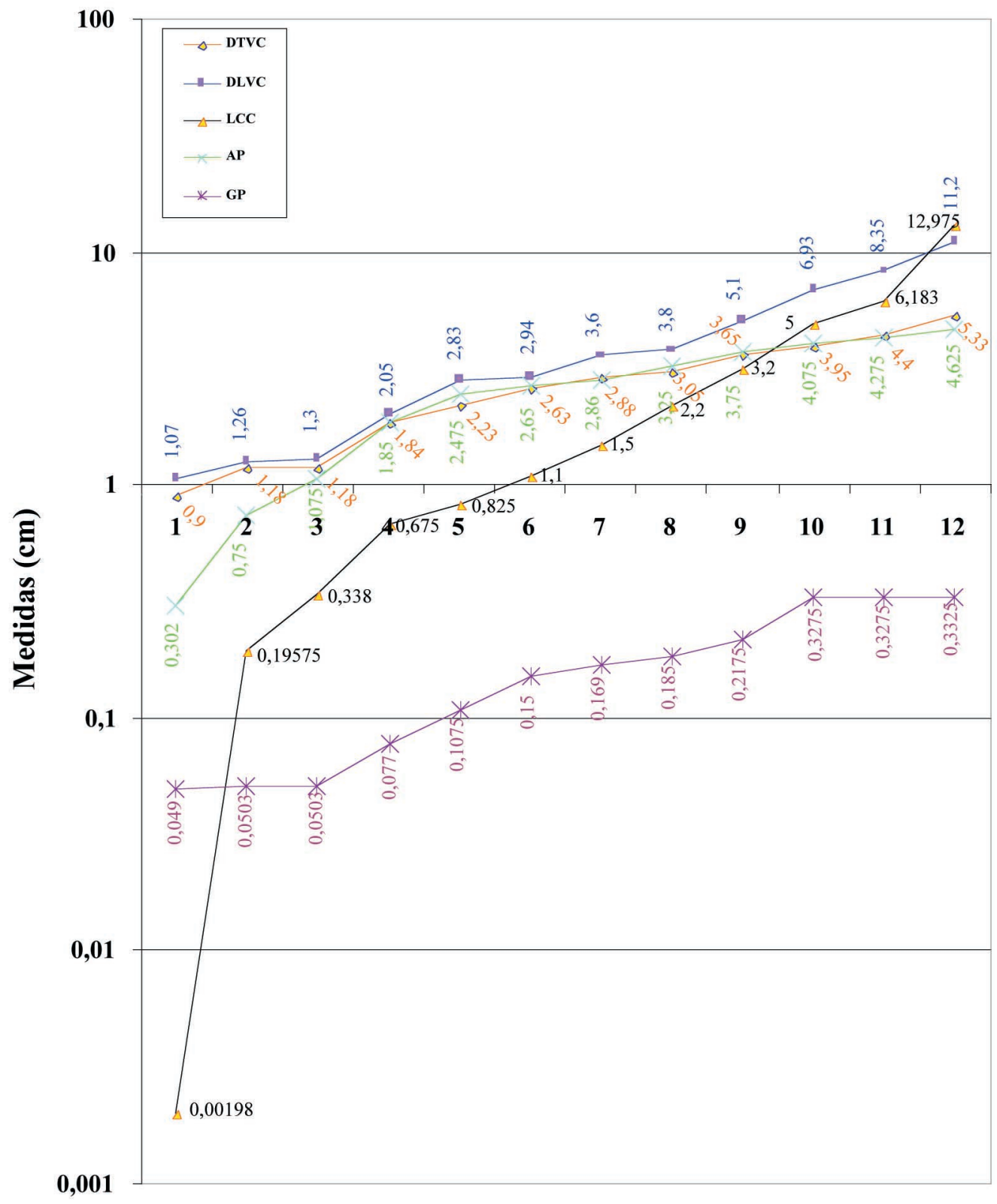

Estadios de Desarrollo

Estadio 4. Embrión somítico de 17 días de gestación: A nivel cefálico, se observan las curvaturas cefálica, cervical y pontina y se diferencian las vesículas encefálicas definitivas: telencéfalo, diencéfalo, mesencéfalo, metencéfalo y mielencéfalo. Al corte histológico transversal, en las vertebras mesenquimáticas, se aprecian las capas ependimaria, del manto y marginal de la médula espinal. En la prominencia cefálica, el proceso frontonasal se ha separado en frontal y nasales; éstos a su vez se subdividen en nasales laterales y nasales mediales que circundan a las fositas olfatorias, bien desarrolladas. Se inicia la fusión de los procesos mandibulares en el plano mediano. A nivel faríngeo, se observan el primer, segundo y tercer arcos branquiales bien definidos, como también la primera, segunda y tercera hendiduras branquiales. El segundo arco branquial está iniciando su crecimiento hacia caudal, para la formación del cuello. Hacia caudal, dentro de 
ILLANES, J.; ORELLANA, C.; FERTILIO, B.; LEYTON, V. \& VENEGAS, F. Análisis macroscópico y microscópico del desarrollo embrionario y fetal en el gato (Felis catus), en relación con el desarrollo de la vesícula coriónica y de la placenta. Int. J. Morphol., 25(3):467-481, 2007.

Gráfico II. Correlación entre el Peso de la Placenta y el Peso del feto en Felis catus

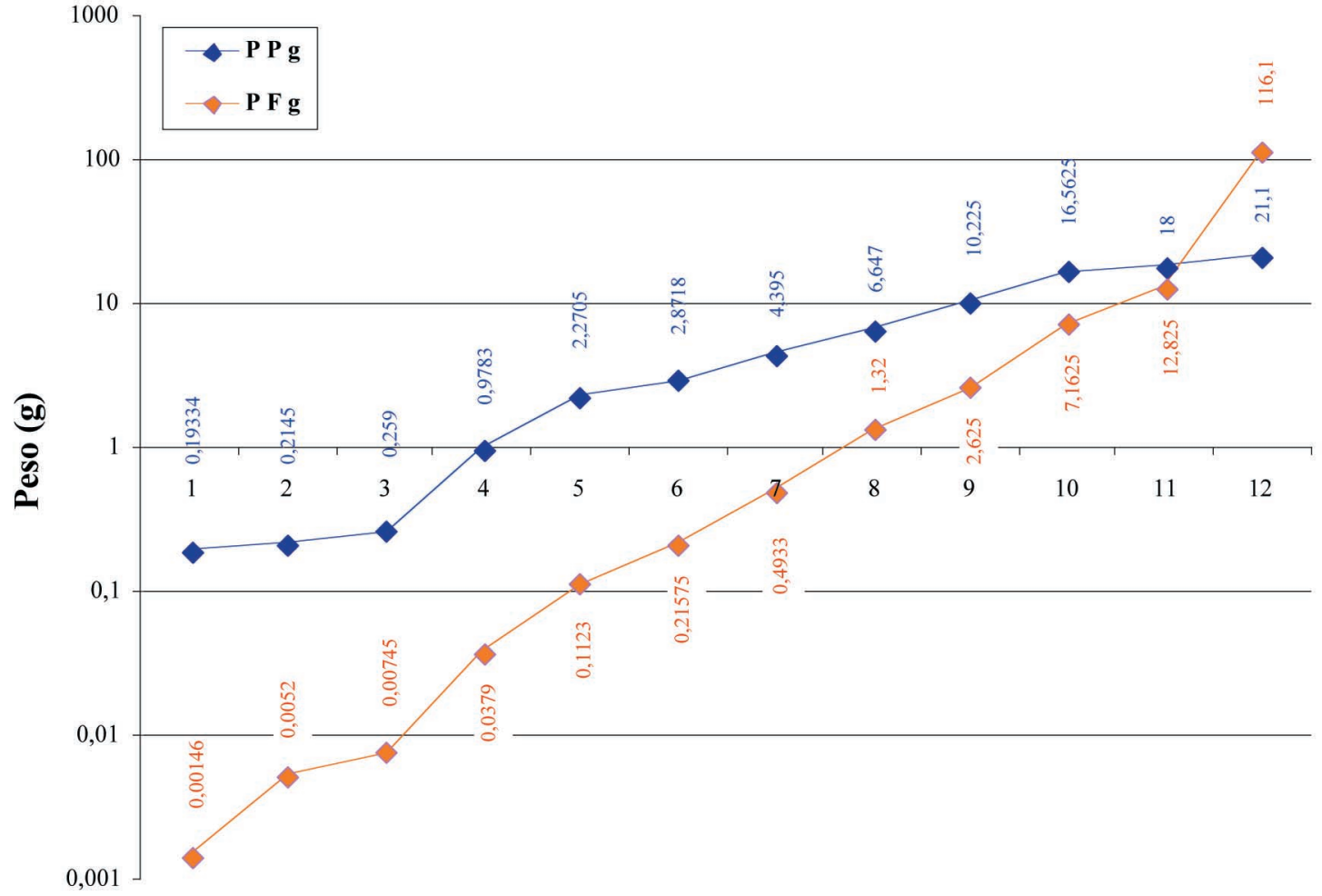

Estadios de desarrollo

Tabla III. Muestra los coeficientes de correlación lineal (r) entre las variables analizadas durante el desarrollo embrionario y fetal en el gato (Felis catus) con un p < 0.0001. Embrión: PF (peso fetal) y LCC (longitud cráneocaudal). Vesícula coriónica: PT (perímetro transversal), DT (diámetro transversal) y DL (diámetro longitudinal). Placenta: PP (peso de la placenta), AP (ancho de la placenta) y GP (grosor de la placenta).

\begin{tabular}{|c|c|c|c|c|c|c|c|c|}
\hline & \multicolumn{2}{|c|}{ EMBRIÓN } & \multicolumn{3}{|c|}{ VESÍCULA CORIÓNICA } & \multicolumn{3}{|c|}{ PLACENTA } \\
\hline & PF & LCC & PT & DT & DL & $\mathbf{P P}$ & $\mathbf{A P}$ & GP \\
\hline $\mathrm{PF}(\mathrm{r})$ & & 0.9038 & 0.6574 & 0.6411 & 0.7667 & 0.6634 & 0.4990 & 0.5446 \\
\hline $\mathrm{p}=$ & 1.0 & 0.0000 & 0.0000 & 0.0000 & 0.0000 & 0.0000 & 0.0002 & 0.0000 \\
\hline $\mathrm{LCC}(\mathrm{r})$ & 0.9038 & \multirow{2}{*}{1.0} & 0.8896 & 0.8788 & 0.9629 & 0.9158 & 0.7777 & 0.8408 \\
\hline $\mathrm{p}=$ & 0.0000 & & 0.0000 & 0.0000 & 0.0000 & 0.0000 & 0.0000 & 0.0000 \\
\hline PT (r) & 0.6574 & 0.8896 & \multirow{2}{*}{1.0} & 0.9955 & 0.9647 & 0.9423 & 0.9674 & 0.9628 \\
\hline $\mathrm{p}=$ & 0.0000 & 0.0000 & & 0.0000 & 0.0000 & 0.0000 & 0.0000 & 0.0000 \\
\hline $\mathrm{DT}(\mathrm{r})$ & 0.6411 & 0.8788 & 0.9955 & 1.0 & 0.9561 & 0.9377 & 0.9696 & 0.9625 \\
\hline $\mathrm{p}=$ & 0.0000 & 0.0000 & 0.0000 & & 0.0000 & 0.0000 & 0.0000 & 0.0000 \\
\hline $\mathrm{DL}(\mathrm{r})$ & 0.7667 & 0.9629 & 0.9647 & 0.9561 & \multirow{2}{*}{1.0} & 0.9773 & 0.8933 & 0.9436 \\
\hline $\mathrm{p}=$ & 0.0000 & 0.0000 & 0.0000 & 0.0000 & & 0.0000 & 0.0000 & 0.0000 \\
\hline $\mathrm{PP}(\mathrm{r})$ & 0.6634 & 0.9158 & 0.9423 & 0.9377 & 0.9773 & \multirow{2}{*}{1.0} & 0.8863 & 0.9678 \\
\hline $\mathrm{p}=$ & 0.0000 & 0.0000 & 0.0000 & 0.0000 & 0.0000 & & 0.0000 & 0.0000 \\
\hline $\mathrm{AP}(\mathrm{r})$ & 0.4990 & 0.7777 & 0.9674 & 0.9696 & 0.8933 & 0.8863 & & 0.9465 \\
\hline $\mathrm{p}=$ & 0.0002 & 0.0000 & 0.0000 & 0.0000 & 0.0000 & 0.0000 & 1.0 & 0.0000 \\
\hline GP (r) & 0.5446 & 0.8808 & 0.9628 & 0.9625 & 0.9436 & 0.9678 & 0.9465 & \\
\hline $\mathrm{p}=$ & 0.0000 & 0.0000 & 0.0000 & 0.0000 & 0.0000 & 0.0000 & 0.0000 & 1.0 \\
\hline
\end{tabular}

la cavidad pericárdica es posible observar el inicio del tabicamiento cardiaco. El intestino medio está prácticamente cerrado, pudiendo observarse el alantoides muy desarrollado. Se observan las yemas de los miembros como pequeños solevantamientos en la pared ventrolateral del cuerpo; las anteriores, más avanzadas, se ubican entre los 8 y 12 pares de somitos, y las inferiores entre los 28 y 30 pares de somitos. El embrión presenta cola. Figs. 4, 16, 26 y 40. 

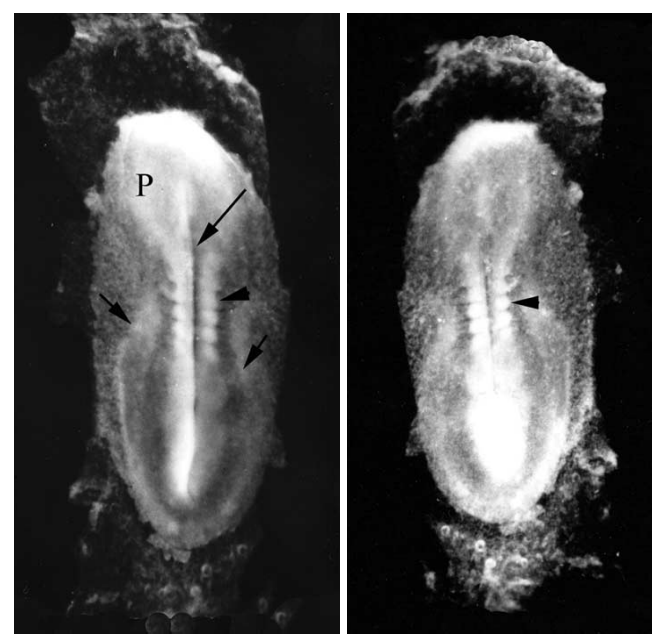

Fig. 1a. (Estadio 1).Vista dorsal y Fig. 1b. Vista ventral de una gástrula tardía de 13 días de gestación. Placa neural (P); surco neural (flecha larga), somito (cabeza de flecha) y esbozo del amnios (flechas cortas).
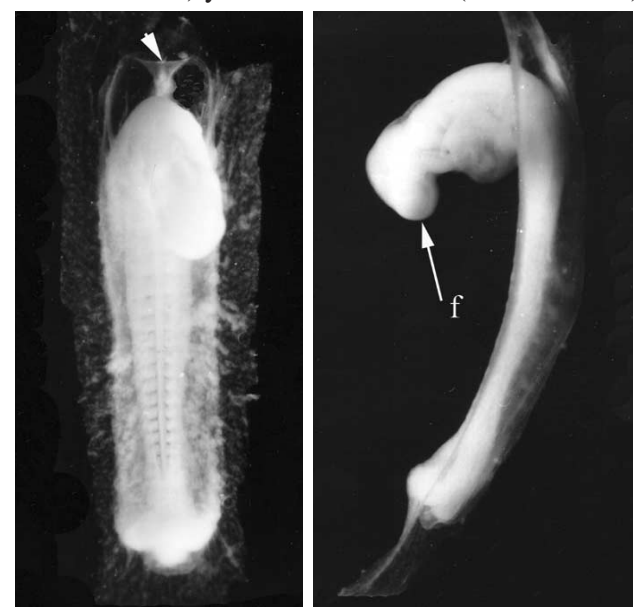

Fig. 3a. (Estadio 3). Vista ventral y Fig. 3b. Vista lateral de un embrión somítico de 16 días de gestación. Proceso frontonasal (f); amnios en el punto de cierre (cabeza de flecha).

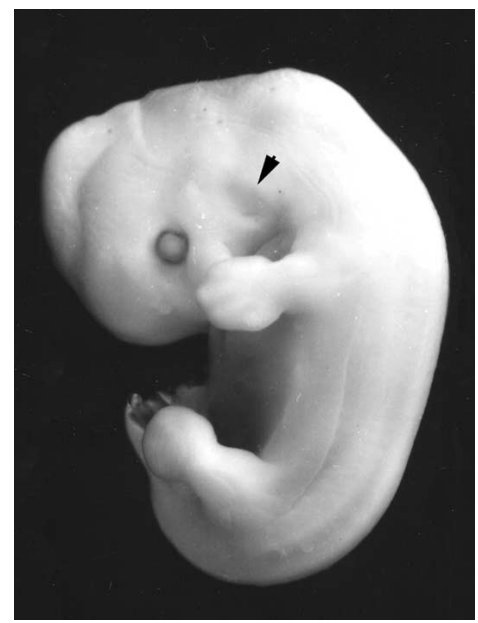

Fig. 6. (Estadio 6). Vista lateral de un embrión prefetal de 19 días de gestación. Formación del pabellón auricular (cabeza de flecha).
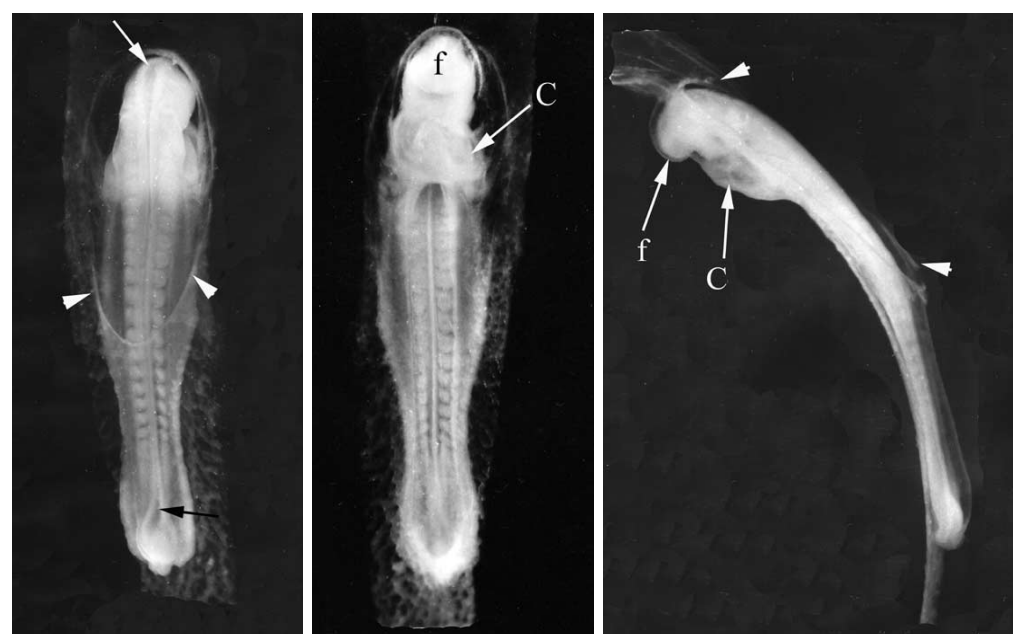

Fig. 2a. (Estadio 2) Vista dorsal, Fig. 2b. Vista ventral y Fig. 2c. Vista lateral de un embrión somítico de 15 días de gestación. Proceso frontonasal (f); asa cardiaca (C); neuroporos anterior y posterior (flechas); amnios (cabezas de flechas).

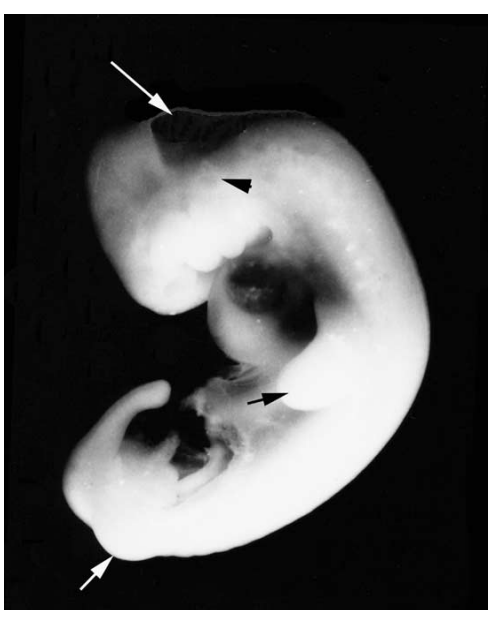

Fig. 4. (Estadio 4). Vista lateral de un embrión somítico de 17 días de gestación. Vesícula ótica (cabeza de flecha); IV ventrículo (flecha larga) y esbozo de miembros (flechas cortas).

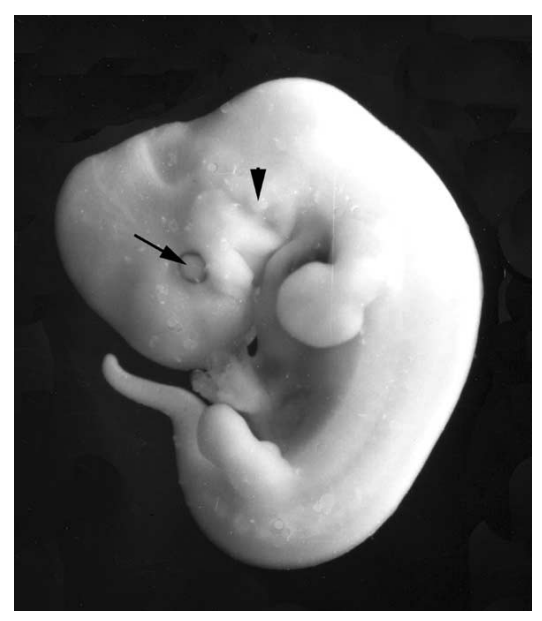

Fig. 5. (Estadio 5). Vista lateral de un embrión prefetal de 18 días de gestación. Lente (flecha); mamelones del esbozo de pabellón auricular (cabeza de flecha).

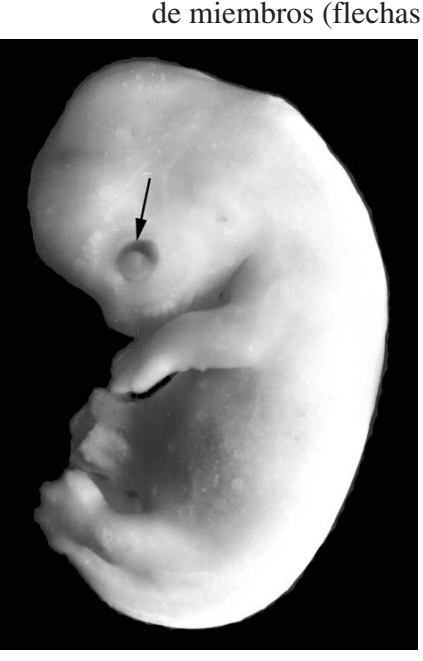

Fig. 7. (Estadio 7). Vista lateral de un embrión prefetal avanzado de 20 días de gestación. Formación de los párpados (flecha).

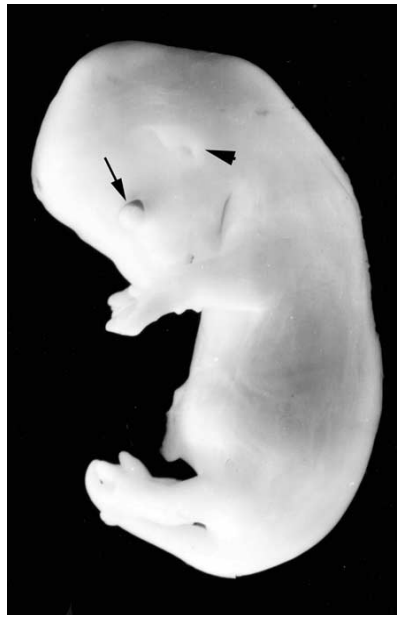

Fig. 8. (Estadio 8)Vista lateral de un embrión prefetal de 24 días de gestación. Párpados (flecha); pabellón auricular (cabeza de flecha).

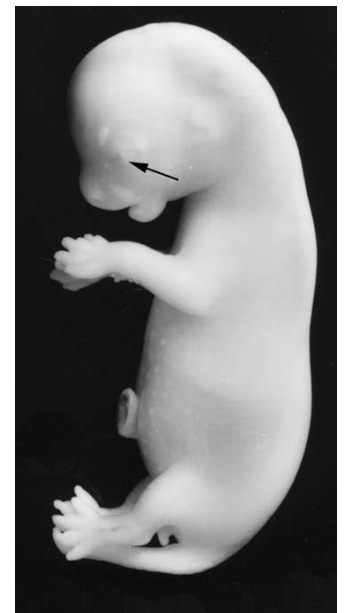

Fig. 9. (Estadio 9).Vista lateral de un feto de 28 días de gestación. Cierre de los párpados (flecha). 


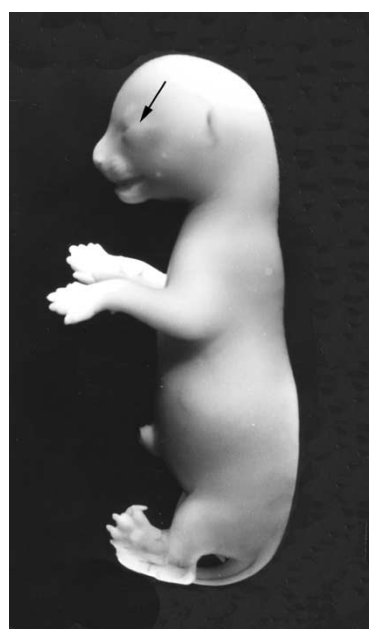

Fig. 10. (Estadio 10). Vista lateral de un feto temprano de 34 días de gestación. Párpados cerrados (flecha).

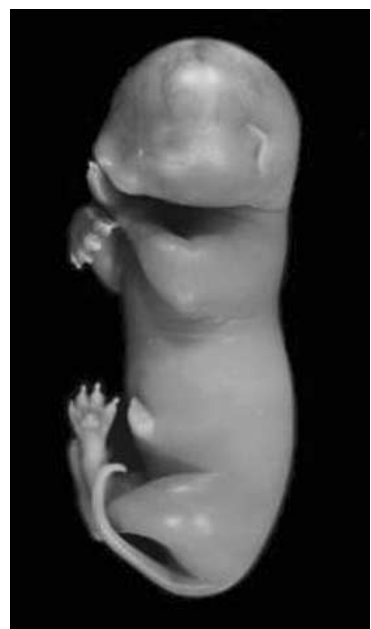

Fig. 11. Vista lateral de un feto de 40 días de gestación. En los miembros se observan las garras retráctiles y cojinetes plantares.

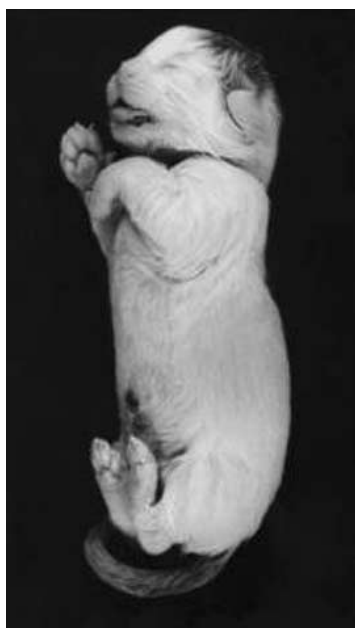

Fig. 12. (Estadio 12). Vista lateral de un feto a término de 60 días de gestación, con cuerpo cubierto de pelos.



Fig. 13. Muestra la vesícula coriónica cubierta por la pared uterina; desprovista de dicha pared, mostrando la placenta a modo de cinturón ecuatorial, y abierta, en cuyo interior presenta un embrión de 13 días de gestación (Estadio 1).



Fig. 15. Muestra la vesícula coriónica cubierta por la pared uterina; desprovista de dicha pared mostrando la placenta a modo de cinturón ecuatorial, y abierta, en cuyo interior presenta un embrión de 16 días de gestación (Estadio 3).

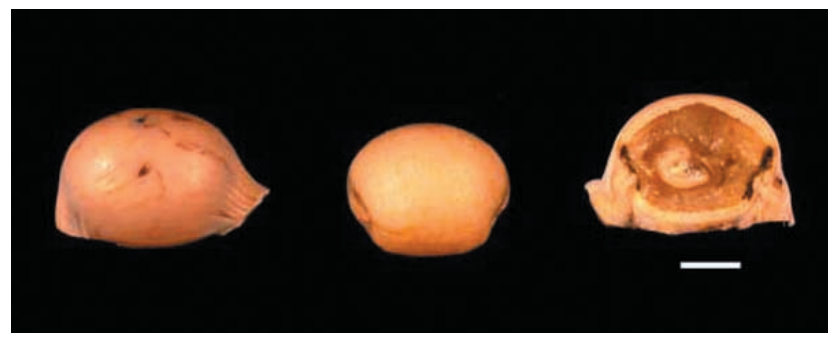

Fig. 17. Muestra la vesícula coriónica cubierta por la pared uterina; desprovista de dicha pared mostrando la placenta a modo de cinturón ecuatorial, y abierta, en cuyo interior presenta un embrión de 18 días de gestación (Estadio 5).

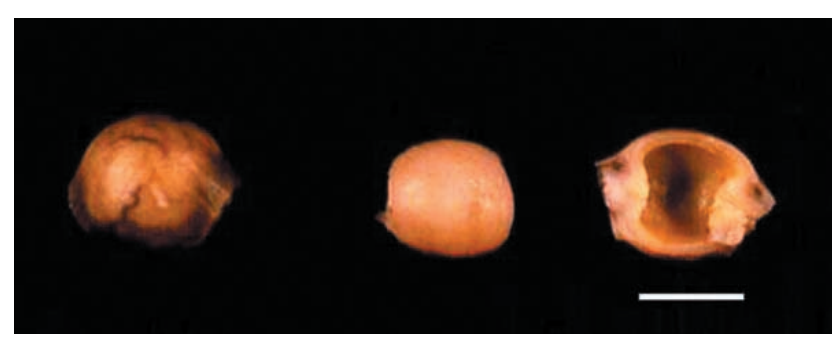

Fig. 14. Muestra la vesícula coriónica cubierta por la pared uterina; desprovista de dicha pared mostrando la placenta a modo de cinturón ecuatorial, y abierta, en cuyo interior presenta un embrión de 15 días de gestación (Estadio 2).

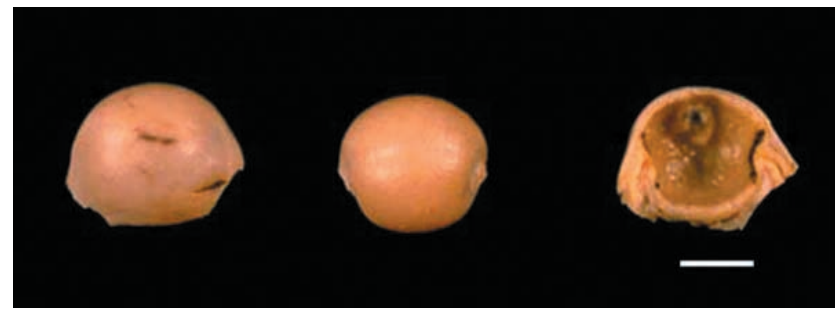

Fig. 16. Muestra la vesícula coriónica cubierta por la pared uterina; desprovista de dicha pared mostrando la placenta a modo de cinturón ecuatorial, y abierta, en cuyo interior presenta un embrión de 17 días de gestación (Estadio 4).

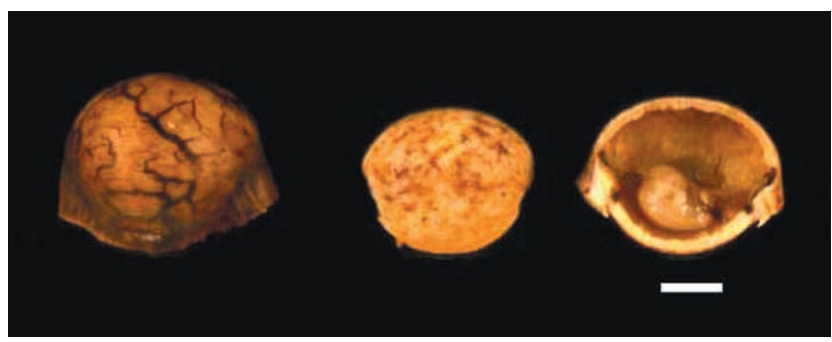

Fig. 18. Muestra la vesícula coriónica cubierta por la pared uterina; desprovista de dicha pared mostrando la placenta a modo de cinturón ecuatorial, y abierta, en cuyo interior presenta un embrión de 19 días de gestación (Estadio 6). 
Estadio 5. Embrión prefetal o metamórfico inicial de 18 días de gestación: A nivel cefálico, se inicia la formación de la cara. Los procesos mandibulares están fusionados en el plano mediano. Los procesos frontal, nasales mediales y laterales se observan claramente. Se observa el surco óculo-naso-oral. El bulbo ocular muestra la pigmentación de la retina, presenta lente y se encuentra entre los procesos maxilar y nasal lateral. A nivel faríngeo, la primera hendidura branquial está rodeada por el primer y segundo arcos faríngeos, en éstos se observan los mamelones $1,2,3$ y $4,5,6$, respectivamente, que constituyen el esbozo del pabellón auricular. Hacia caudal, el corazón está tabicado. El cuerpo del embrión se presenta totalmente delimitado y el cordón umbilical constituido. Los esbozos de los miembros se observan más cilíndricos y alargados, los anteriores presentan forma de paleta en su extremo distal. Los miebros posteriores menos desarrollados. Figs. 5, 17, 27, 41 y 42.

Estadio 6. Embrión prefetal de 19 días de gestación: El embrión presenta mayor desarrollo. Se observa la conformación de la cara; el surco oculo-naso-oral cerrado, en el bulbo ocular la retina está más pigmentada, se están formando los párpados; las fosas nasales se sitúan más anteriores y el pabellón auricular presenta mayor desarrollo. En el tronco, se observa una gran prominencia ventral debido al gran tamaño del hígado, lo que genera la aparición de la hernia umbilical fisiológica. A nivel del cordón umbilical, se observan dos arterias y una vena (vena umbilical izquierda). Los miembros se presentan más alargados y las paletas de las manos y pies, miran hacia medial, se puede observar la flexión del codo y del corvejón, respectivamente. En el extremo distal de los miembros anteriores y posteriores se observan los rayos digitales con zonas claras que corresponden a las membranas interdigitales. Los miembros posteriores presentan menor desarrollo. Al corte histológico transversal, se aprecia el cuerpo de la vértebra en etapa cartilaginosa. Figs. 6, 18 y 43.

Estadio 7. Embrión prefetal de 20 días de gestación: Embrión con mayor desarrollo y adquiere paulatinamente las características propias de su especie. La cabeza es menos prominente en proporción al tamaño del cuerpo. La cara se observa más desarrollada. Los bulbos oculares adoptan una posición más anterior, mayor pigmentación de la retina, se observa claramente la vesícula del lente y los párpados están más desarrollados. Las fosas nasales han adoptado una posición anterior y se han alejado de los bulbos oculares. El pabellón auricular sobresale de la superficie corporal. Es posible observar el meato acústico externo. Se han conformado la mandíbula y el hocico. Se observa un área de folículos pilosos en la parte anterior de la mejilla, que corresponde a los bigotes. Hacia caudal, aún se observa la presencia de la hernia umbilical fisiológica. Los miembros anteriores presentan una clara flexión del codo, las manos se curvan sobre el tórax y los dígitos están separados. Comienzan a esbozarse los cojinetes plantares. Los miembros posteriores presentan una clara flexión del corvejón, los rayos digitales se aprecian perfectamente y se inicia la separación de los dígitos. Caudalmente, se observa el esbozo del tubérculo genital. Al corte histológico transversal, se aprecian el cuerpo y arco de la vértebra en etapa cartilaginosa. Figs. 7, 19, 28 y 44.

Estadio 8. Embrión prefetal avanzado de 24 días de gestación: El desarrollo de la cara adquiere las características propias del felino. Los párpados permanecen abiertos. El pabellón auricular se encuentra plegado en su extremo apical, se puede observar el meato acústico externo. Se observan con claridad los folículos pilosos de los bigotes. En los miembros anteriores, los dígitos están separados, los cojinetes plantares adquieren mayor desarrollo y se observa el esbozo de las garras. Los miembros posteriores presentan los dígitos separados. No hay presencia de cojinetes plantares ni de garras. Figs. 8, 20, 29 y 45.

Estadio 9. Feto de 28 días de gestación: Se observa gran desarrollo de la cara. La boca se presenta abierta, se puede apreciar la lengua. Los párpados están casi cerrados. El pabellón auricular se presenta más desarrollado y plegado en dirección al bulbo ocular. Aparición de folículos pilosos en diversas áreas corporales. En la región ventral del tórax y abdomen se observa el esbozo de cuatro pares de glándulas mamarias. La hernia umbilical fisiológica comienza a involucionar. Los miembros se encuentran totalmente libres. Hay mayor diferenciación de las garras y los cojinetes se encuentran totalmente formados. En los miembros anteriores se observan cinco dígitos, mientras que en los posteriores sólo cuatro. Caudalmente, se observa el tubérculo genital. Figs. 9, 21 y 30.

Estadio 10. Feto de 34 días de gestación: Notoria disminución en el tamaño de la cabeza en proporción al tamaño corporal. La cara presenta la conformación de un felino. Los párpados están totalmente cerrados. El pabellón auricular se presenta solevantado en su porción apical. Comienza a aparecer el pelo grueso de los bigotes y cejas. Los folículos pilosos se han desarrollado en toda la superficie corporal. La hernia umbilical fisiológica ha involucionado completamente. Los miembros se encuentran bien desarrollados. Los codos señalan en dirección caudal y las rodillas en dirección craneal. Se aprecia la característica retráctil de las garras. Figs. 10 y 22. 


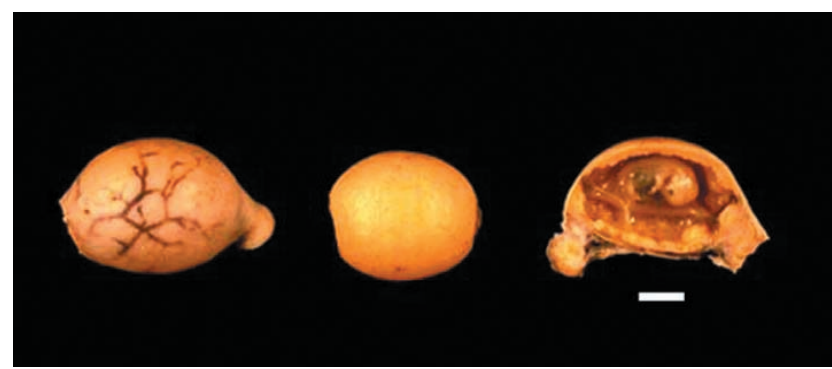

Fig. 19. Muestra la vesícula coriónica cubierta por la pared uterina; desprovista de dicha pared mostrando la placenta a modo de cinturón ecuatorial, y abierta, en cuyo interior presenta un embrión de 20 días de gestación (Estadio 7).

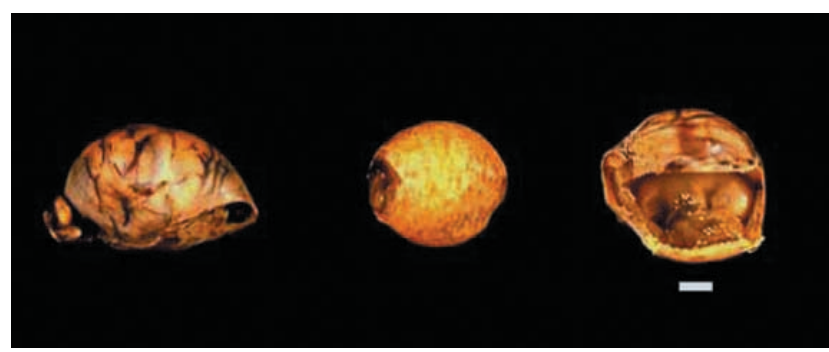

Fig. 21. Muestra la vesícula coriónica cubierta por la pared uterina; desprovista de dicha pared mostrando la placenta a modo de cinturón ecuatorial, y abierta, en cuyo interior presenta un embrión de 28 días de gestación (Estadio 9).

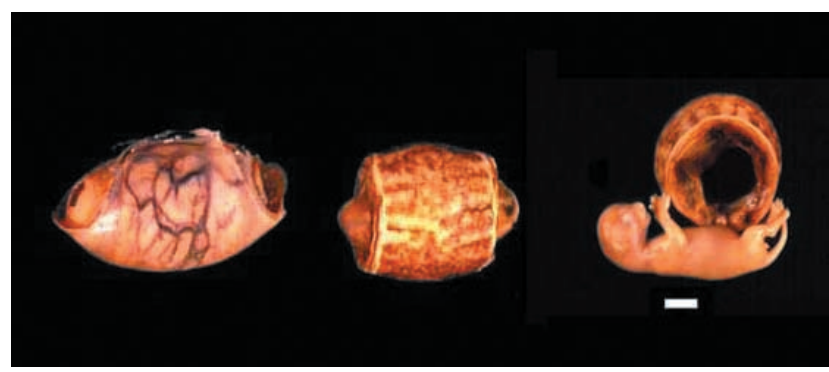

Fig. 23. Muestra la vesícula coriónica cubierta por la pared uterina; desprovista de dicha pared mostrando la placenta a modo de cinturón ecuatorial, y abierta, en cuyo interior presenta un feto de 40 días de gestación (Estadio 11).

Estadio 11. Feto de 40 días de gestación: Los párpados permanecen completamente cerrados. El pabellón auricular permanece con su extremo apical solevantado. Los bigotes han crecido. Se observa la presencia de cejas pero no de pestañas y de folículos pilosos en toda la superficie corporal. En los miembros, los cojinetes han alcanzado mayor desarrollo y las garras están muy bien constituidas y cornificadas. Fig. 11 y 23.

Estadio 12. Feto a término de 60 días de gesta-

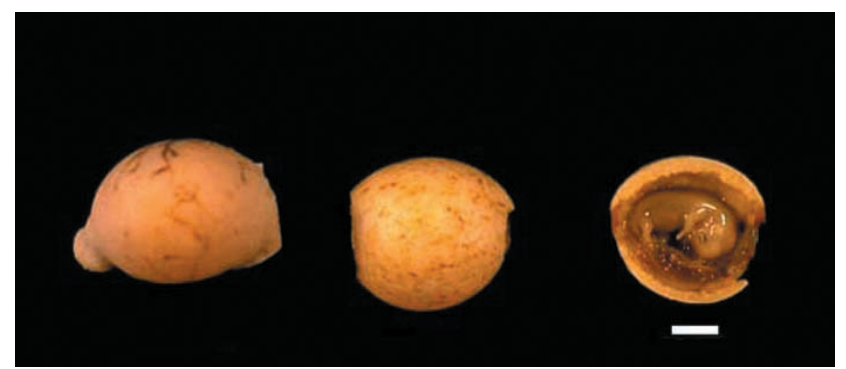

Fig. 20. Muestra la vesícula coriónica cubierta por la pared uterina; desprovista de dicha pared mostrando la placenta a modo de cinturón ecuatorial, y abierta, en cuyo interior presenta un embrión de 24 días de gestación (Estadio 8).



Fig. 22. Muestra la vesícula coriónica cubierta por la pared uterina; desprovista de dicha pared mostrando la placenta a modo de cinturón ecuatorial, y abierta, en cuyo interior presenta un feto de 34 días de gestación (Estadio 10).

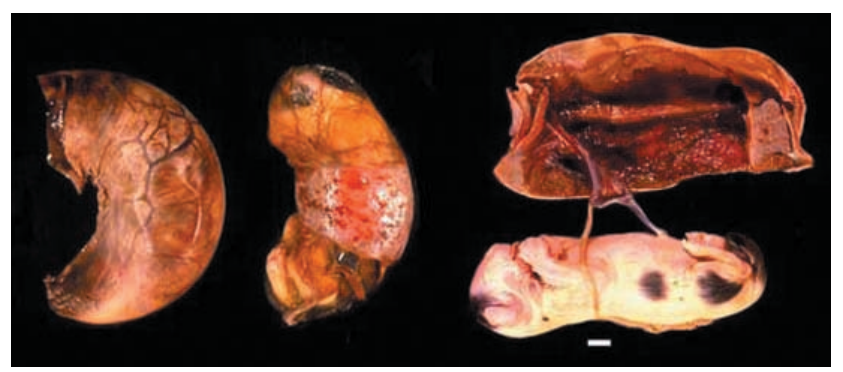

Fig. 24. Muestra la vesícula coriónica cubierta por la pared uterina; desprovista de dicha pared mostrando la placenta a modo de cinturón ecuatorial, y abierta en cuyo interior presenta un feto de 60 días de gestación (Estadio 12).

ción: Los párpados permanecen cerrados. Existe una diferencia del doble del tamaño entre este estadio y el anterior. El aspecto del feto es similar al de un neonato. Todo el cuerpo se encuentra cubierto por pelos gruesos, largos y pigmentados. Los cojinetes están pigmentados. Se aprecian claramente los genitales externos y las glándulas mamarias. Figs. 12 y 24 .

Formación de la cara y del cuello: En el gato, la cara y el cuello se forman entre los estadios 3 a 9 del desarrollo (16 a 28 días de gestación). Figs. 25 a la 30. 


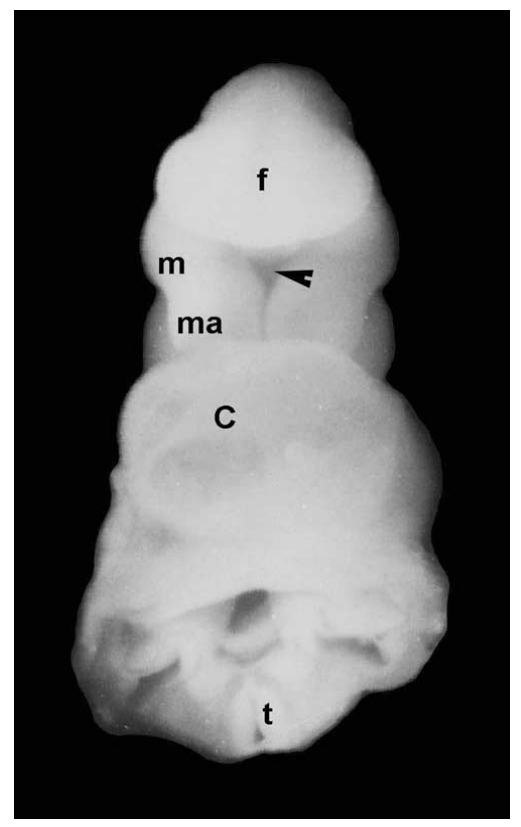

Fig. 25. Estadio 3. Vista ventral de la región faríngea de un embrión de 16 días de gestación. Se observa el estomodeo (cabeza de flecha), delimitado cranealmente por el proceso frontonasal (f), lateralmente por los procesos maxilares (m) y ventralmente por los procesos mandibulares (ma), aún sin fusionarse en la línea media. Prominencia cardiaca (C). Tubo nervioso (t).

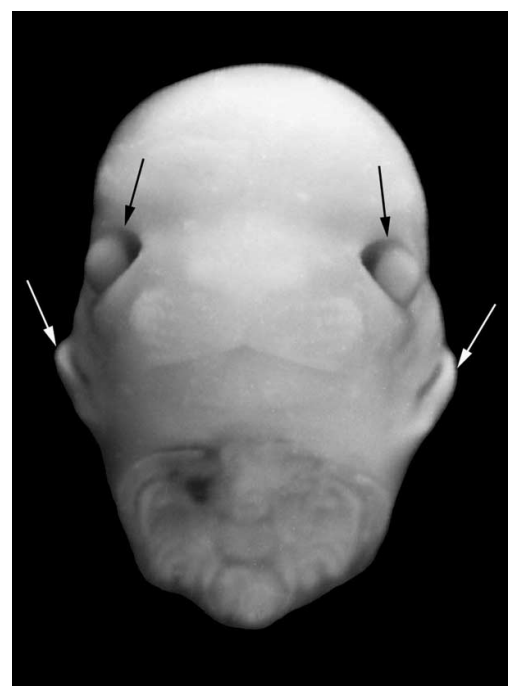

Fig. 28. Estadio 7. Vista ventral de la región cefálica de un embrión de 20 días de gestación. Se observan los ojos en una posición más anterior y los párpados más desarrollados (flechas negras). Las fosas nasales se ubican en la línea media. Se ha formado el hocico; sobre éste se observan folículos pilosos. Pabellón auricular (flechas blancas).

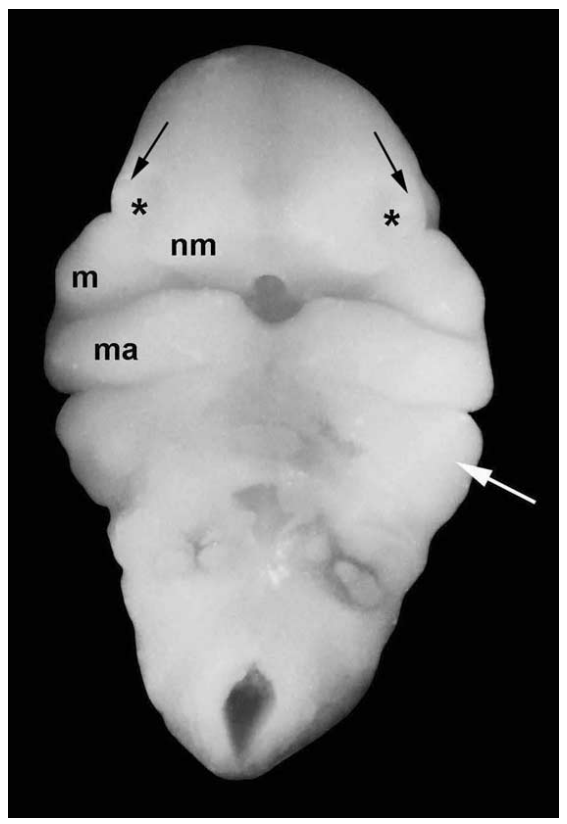

Fig. 26. Estadio 4. Vista ventral de la región faríngea de un embrión de 17 días de gestación. El estomodeo está delimitado por los procesos nasomediales (nm), maxilares (m) y mandibulares (ma). Entre los procesos nasolaterales (flechas negras) y nasomediales (nm) se observan las fositas olfatorias (asteríscos). En la región faríngea se muestra el segundo arco branquial (flecha blanca).

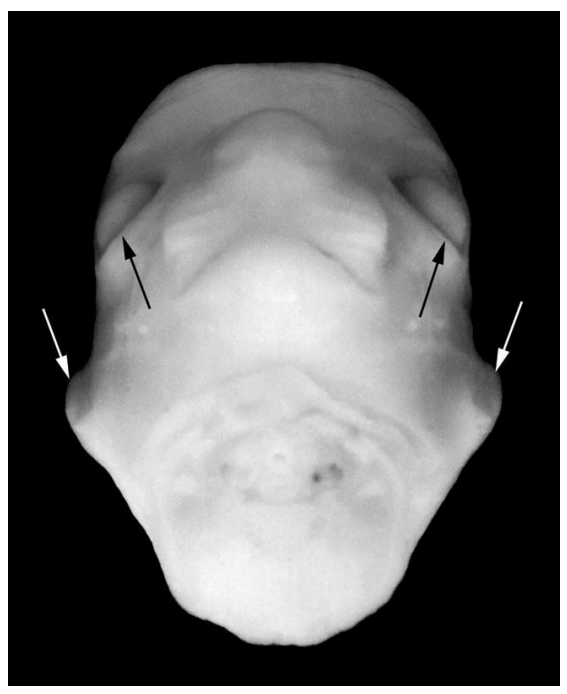

Fig. 29. Estadio 8. Vista ventral de la región cefálica de un embrión de 24 días de gestación. Se observan las características propias de la especie. Los párpados permanecen abiertos (flechas negras). Se observan folículos pilosos sobre y bajo el hocico. El pabellón auricular se encuentra plegado en su extremo apical (flechas blancas).

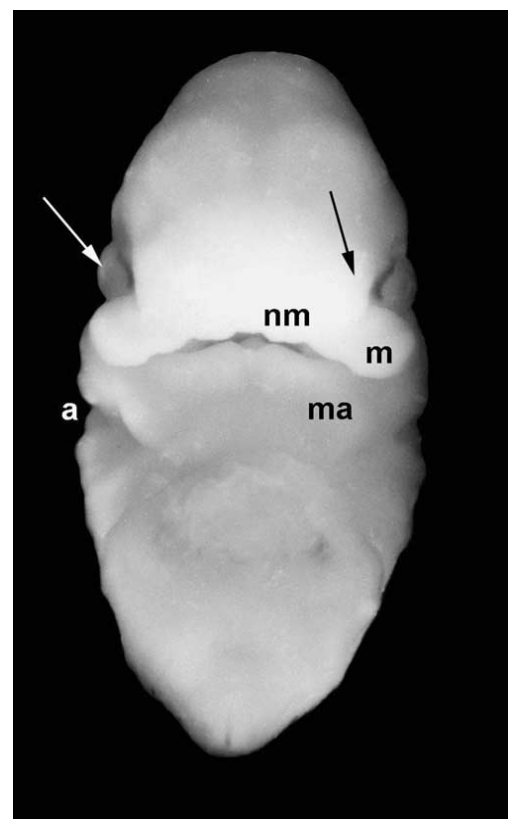

Figu. 27. Estadio 5. Vista ventral de la región faríngea de un embrión de 18 días de gestación. Se observan los procesos nasomedial $(\mathrm{nm})$, nasolateral (flecha negra) y maxilar (m). Los procesos mandibulares (ma), están fusionados en la línea media. En los ojos se observa el cristalino (flecha blanca). Mamelones del esbozo del pabellón auricular (a).

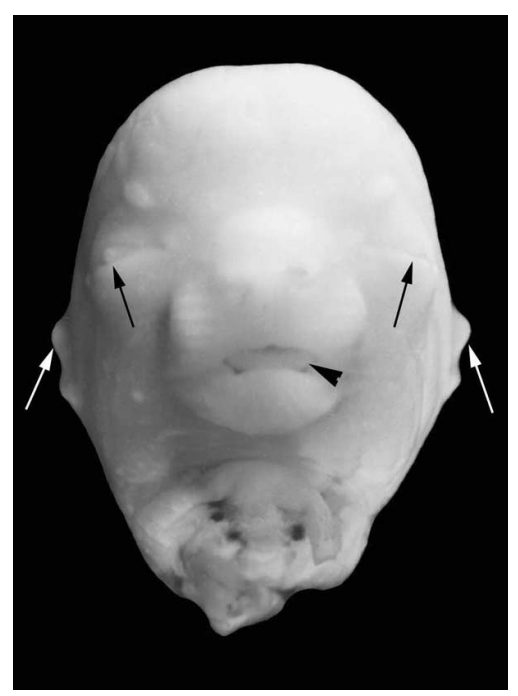

Fig. 30. Estadio 9. Vista ventral de la región cefálica de un embrión de 28 días de gestación. Se observa gran desarrollo de la cara. Los párpados están casi cerrados (flechas negras). Se observa el esbozo de la lengua dentro de la cavidad oral (cabeza de flecha) y el pabellón auricular plegado en dirección al ojo (flechas blancas). 
Las Figs. 31 a la 45, muestran cortes histológicos transversales teñidos con H-E, desde el estadio 1 al 8 del desarrollo del gato, donde se pueden observar la diferenciación del sistema nervioso (neurulación), la mesodermogénesis, cambio del esqueleto mesenquimático a cartilaginoso (vértebras), formación del corazón desde tubo endocárdico hasta el tabicamiento de atrios y ventrículos. Diferenciación pulmonar desde etapa embrionaria hasta la etapa seudoglandular.

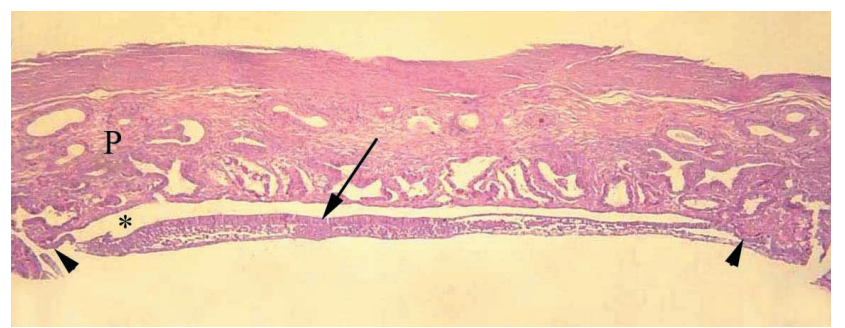

Fig. 31. Estadio 1.

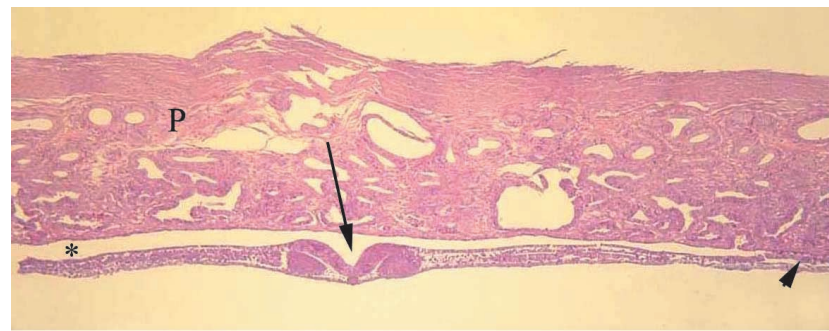

Fig. 32. Estadio 1.

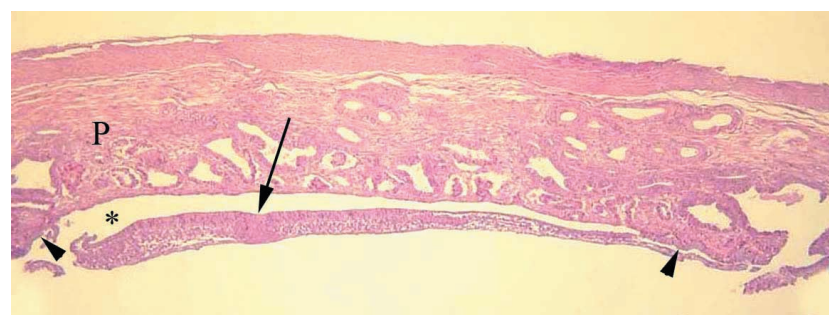

Fig. 33. Estadio 1.

Figs. 31, 32 y 33. Estadio 1. Muestran un embrión trilaminar en tres niveles: placa neural, surco neural y surco primitivo, respectivamente (flechas). En contacto con el embrión trilaminar, la placenta $(\mathrm{P})$ muestra la zona de aposición (*), adhesiva e intrusiva (cabezas de flecha), futuro hematoma marginal. H-E, 100X.

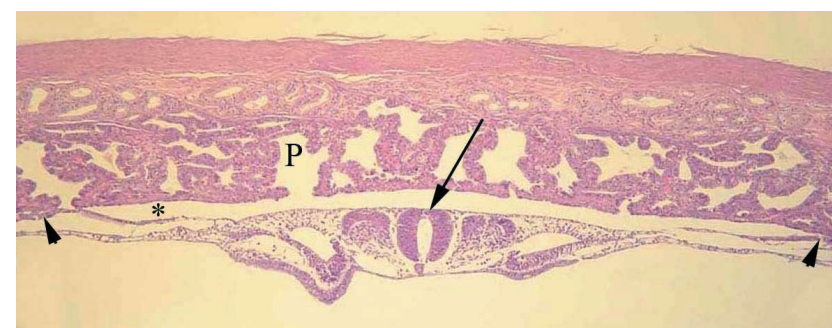

Fig. 34. Estadio 2.

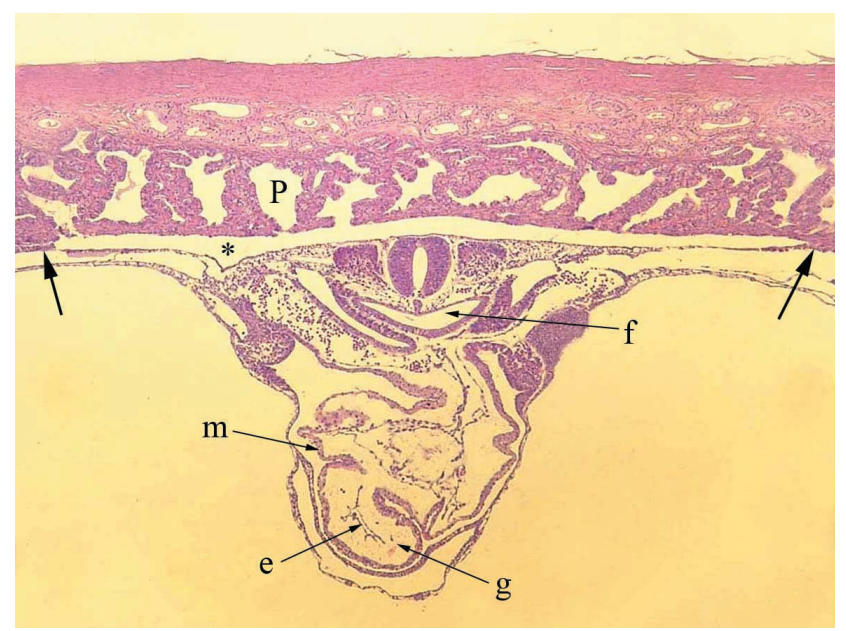

Fig. 35. Estadio 2.

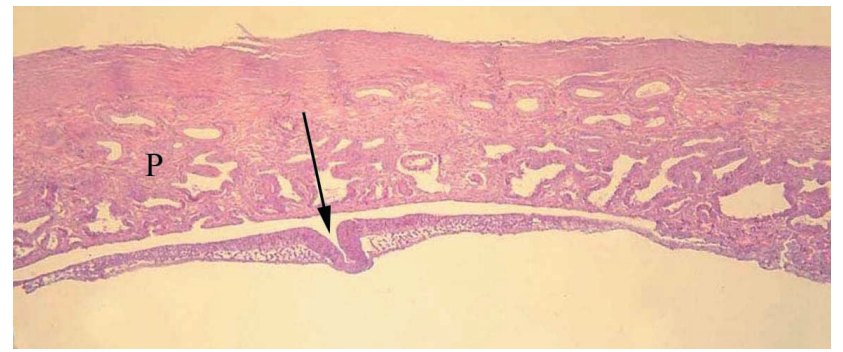

Fig. 36. Estadio 2.

Figs. 34, 35 y 36: Estadio 2. Muestran en un embrión tubular, en tres niveles: en la región posterior, el surco primitivo (flecha); en la región media, la formación del tubo endocárdico con el mesocardio dentro del saco pericárdico; y en la región anterior, se aprecian los somitos, el tubo neural cerrado y la notocorda. El tubo endocárdico presenta endocardio (e), gelatina cardiaca (g) y mioepicardio (m), faringe (f). En contacto con el embrión tubular, la placenta (P) muestran las zonas de aposición (*), adhesiva e intrusiva (cabezas de flecha). H-E, 100X. 

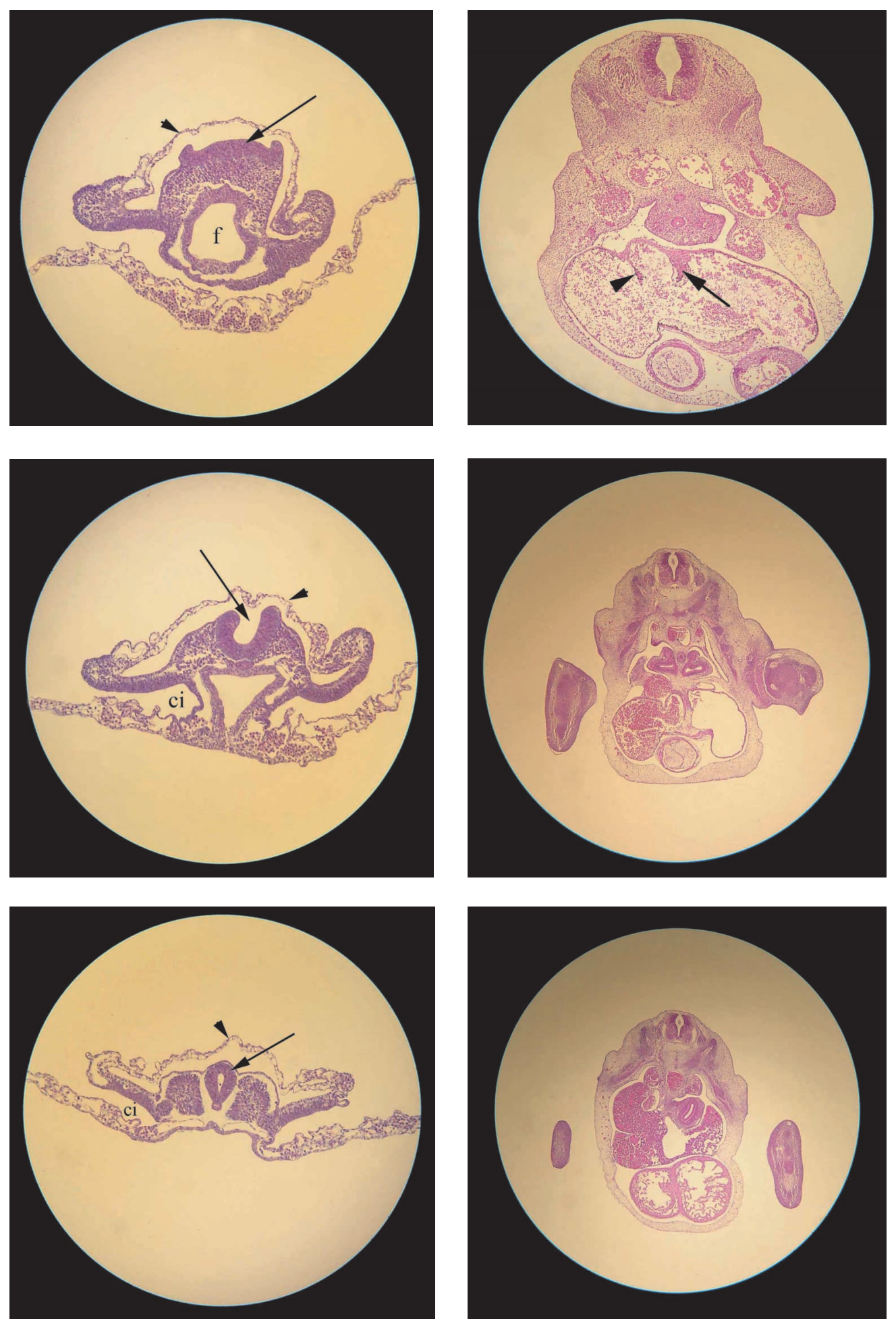

Figs. 37, 38 y 39: Estadio 3. Muestran en un embrión tubular, la placa neural, con sus sus pliegues neurales; surco neural; y tubo neural, respectivamente (flechas). Se aprecia la diferenciación del mesodermo, el celoma intraembrionario (ci), faringe (f), y el amnios totalmente cerrado (cabeza de flecha). H-E, 200X.

Figs. 40, 41 y 42. La Fig. 40, muestra un embrión en Estadio 4, en el que se pueden observar la comunicación interatrial, el septum primum (flecha) y las válvulas del seno venoso en el atrio derecho (cabeza de flecha). La vértebra en etapa mesenquimática, y la médula espinal presenta su histogenesis (capa marginal, del manto y epitelio ependimario). H-E, 100X. Las Figs. 41 y 42, muestran un embrión en Estadio 5, en el que se destaca el tabicamiento de atrios y ventrículos, respectivamente. H-E, 40X. 

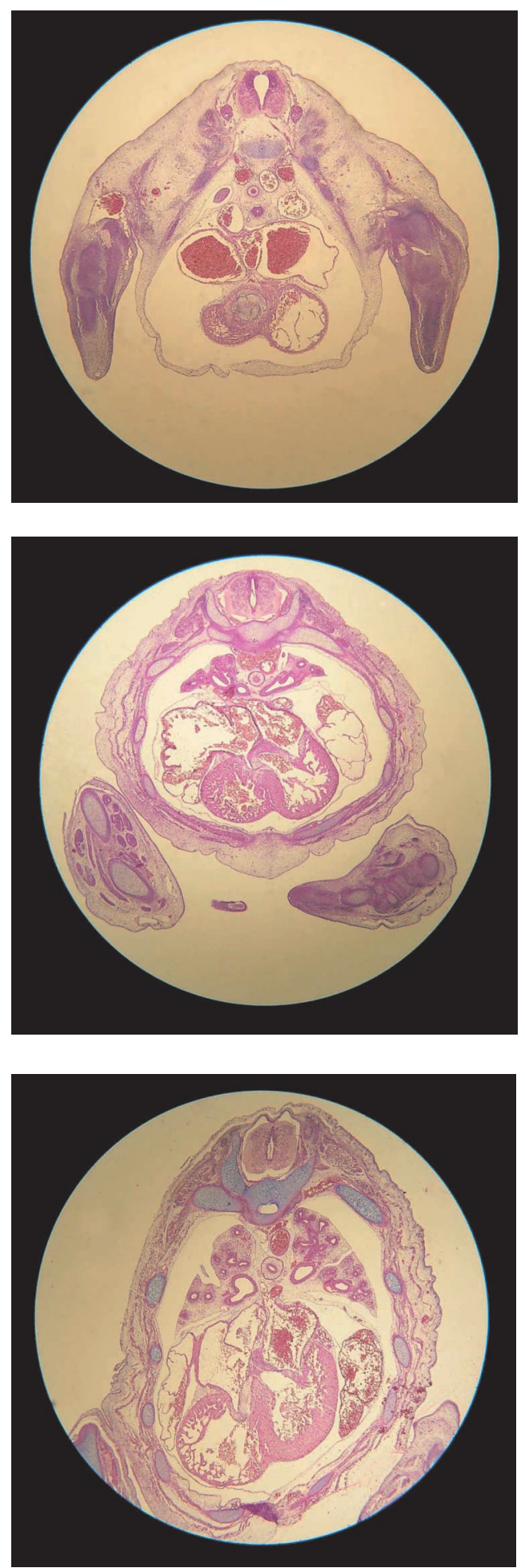

Figuras 43, 44 y 45: Muestran embriones en estadio 6,7 y 8 , respectivamente. En ellos se puede observar el tabicamiento definitivo del corazón; el desarrollo pulmonar desde la etapa embrionaria a seudoglandular; etapa cartilaginosa de las vértebras y gran parte del esqueleto cartilaginoso, como también el desarrollo de los miembros. H-E, 40X.

\section{DISCUSIÓN}

El estudio del desarrollo embrionario y fetal en el gato y su relación con el desarrollo de la vesícula coriónica y de la placenta, permite determinar con mayor exactitud la edad gestacional en esta especie. Estos parámetros son perfectamente utilizables, en forma conjunta, con un método que permite diagnosticar gestación desde etapas muy tempranas, como es la ecografía obstétrica (Yurac \& Pereda, 1984 y Melivilu), dentro del campo de la imagenología. La edad gestacional obtenida de acuerdo a los antecedentes de anamnesis fue corroborada con las características macroscópicas de los úteros grávidos, como también de los embriones y fetos obtenidos. Establecida ésta, fue cotejada mediante la fórmula de Nelson \& Cooper (1975, la cual entrega resultados bastante exactos.

En base a las descripciones realizadas por Denker et al. (1978) y Nodem \& De Lahunta (1990), las fechas de cruza registradas en las fichas control y las características de los embriones y fetos, se determinó que la edad de gestación para el estadio 1, es de 13 días. No fue posible utilizar la fórmula de Nelson \& Cooper, puesto que sólo permite calcular gestaciones mayores o iguales a 15 días. Este estadio corresponde a una gástrula tardía con 3 a 4 pares de somitos bien definidos, de 3,3 $\mathrm{mm}$ de longitud y que muestra además, el surco y la placa neural, lo que indica el inicio de los procesos de mesodermogénesis y neurulación, respectivamente. En efecto, Nodem \& De Lahunta y Denker $e t$ al. observaron las 3 hojas germinativas y la néurula alrededor de los 12 y 14 días postcópula, respectivamente. En este estadio se inicia la formación del amnios por plegamiento (plectamnios). Nodem \& De Lahunta observaron la formación del amnios y corion cuando el embrión medía $4 \mathrm{~mm}$. La vesícula coriónica en este estadio mide 1.07 x $0.9 \mathrm{~cm}$ en sus diámetros longitudinal y transversal, respectivamente. En este momento se inicia el desarrollo de la placenta. Al corte histológico, se observa la placenta zonaria: aposicional cerca del embrión y adhesiva e intrusiva externamente a él, además de los hematomas marginales. Swanson et al. (1994) señalaron que la placenta del gato se forma a partir del día 16 postcópula y que es una estructura madura al día 20, observándose crecimientos uterinos esféricos externos de $2.5 \pm 1 \mathrm{~cm}$ de diámetro. Thatcher et al. (1991) y Leiser \& Koob (1993) observaron en el día 15 postcópula, crecimientos esféricos edematosos por fuera del útero que medían $1.5 \mathrm{~cm}$ de diámetro, correspondientes al desarrollo placentario, además de los hematomas marginales.

El Estadio 2 corresponde a un embrión somítico plano de 15 días de gestación, 18 pares de somitos y $6.5 \mathrm{~mm}$ de longitud. Se observa la presencia del proceso frontonasal, las placodas nasales, vesículas ótica y óptica, primer y segundo arcos branquiales, y además, el tubo endocárdico dentro de su cavidad pericárdica, con lo cual se inicia el latido cardiaco. Nodem \& De Lahunta mencionaron no haber observado el tubo endocárdico entre los días 15 y 16 de gestación. Verstegen et al. y Melivilu señalaron que el latido cardiaco en el gato se inicia entre los 18 a 25 días de gestación. Sin embargo, con la formación del tubo endocárdico comienza el latido cardiaco.

El Estadio 3 corresponde a un embrión somítico curvo de 16 días de gestación, 26 pares de somitos y $3.38 \mathrm{~mm}$ de longitud. El estomodeo se encuentra delimitado por los pocesos frontonasal, maxilares y mandibulares. Se observan el $1^{\circ}, 2^{\circ}$ y $3^{\circ}$ arco branquial. El tubo endocárdico está incurvado 
dentro de la cavidad pericárdica y el tubo neural está prácticamente cerrado. El amnios en este estadio está cerrado. Vatti (1992) observó el amnios del gato completamente cerrado al día 20 post-cópula.

El Estadio 4 corresponde a un embrión somítico tubular de 17 días de gestación y $0.67 \mathrm{~cm}$ longitud. Los somitos occipitales han desaparecido. Se observan los procesos nasales separados en mediales y laterales. Se inicia la opercularización a partir del $2^{\circ}$ arco branquial y el tabicamiento del corazón. Además, aparecen las yemas de los miembros y, microscópicamente se puede observar el inicio de la histogenesis de la médula espinal. Böhme (1988) observó el término de la etapa de tubo neural alrededor del día 18 post-cópula y el inicio de la histogenesis de la médula en el día 25.

Los Estadios 5, 6, 7, 8 corresponden a un embrión prefetal de 18, 19, 20 y 24 días de gestación, respectivamente, y con $0.82 \mathrm{~cm}, 1.1 \mathrm{~cm}, 1,5 \mathrm{~cm}$ y $2,2 \mathrm{~cm}$ de longitud. En el estadio $5 \mathrm{se}$ inicia la formación de la cara, el bulbo ocular está pigmentado y se observa el lente, aparece el esbozo del pabellón auricular, los miembros presentan forma de paleta, son cilíndricos y alargados. Le médula espinal presenta todas sus capas. Se observa el esbozo mesenquimático del cuerpo vertebral. En el estadio 6 ya se observa mayor conformación de la cara, de los párpados, el pabellón auricular más desarrollado y las fosas nasales en posición frontal. Los miembros presentan rayos digitales y membranas interdigitales. Aparece la hernia umbilical fisiológica y se observa el esbozo cartilaginoso del cuerpo vertebral. En el estadio 7 la cara presenta mayor desarrollo, los bulbos oculares y fosas nasales adquieren una posición frontal. La mandíbula y el hocico están conformados, aparecen los bigotes y el cuello está formado. Se observa la flexión del codo en los miembros anteriores, los dígitos están separados y aparece el esbozo de los cojinetes plantares. La cara muestra el desarrollo propio de la especie en el estadio 8 y los miembros presentan esbozos de garras mirando las plantas hacia el plano mediano.

El estadio 9 corresponde a un feto de 28 días de gestación y $3.2 \mathrm{~cm}$ de longitud. Se observa gran desarrollo de la cara. La boca está abierta y se puede apreciar la lengua. Los párpados están cerrados. Aparecen folículos pilosos en algunas áreas del cuerpo, además del esbozo de la glándula mamaria. Los miembros se encuentran libres.

Los Estadios 10, 11 y 12 corresponden a fetos de 34, 40 y 60 días de gestación y 5, 6.2 y $13 \mathrm{~cm}$ de longitud, respectivamente.

Respecto de algunos parámetros utilizados en ecografía obstétrica, Melivilu por medio de esta técnica observó embriones de $5 \mathrm{~mm}$ de largo occípito-coccígeo el día 15 de gestación. A los 20, 30 y 40 días observó embriones de 9, 31 y $61 \mathrm{~mm}$ de largo, respectivamente. Estas cifras están muy cercanas a las obtenidas por nosotros en embriones y fetos de similar edad observados en forma directa. Las diferencias pueden deberse a que el cálculo de los días de gestación es realizado por algunos autores a partir de la primera cópula durante el primer día del celo en la gata, pero en la mayoría de los casos la cópula efectiva se produce en el tercer día, ya que el momento de la ovulación es bastante variable (Sojka et al., 1970; Hamner et al., 1970; Paape et al., 1975; Wildt et al., 1980; Goodrowe et al., 1988; Swanson et al. y Roth et al., 1994).

Estos parámetros obtenidos en el desarrollo embrionario y fetal del gato, son un aporte para el diagnóstico de gestación, determinación de la edad y pueden ser empleados como complemento a otros métodos de diagnóstico de edad gestacional, como la ecografía. El análisis estadístico de correlación lineal (r) de las variables analizadas en estos estadios presenta un alto grado de significancia $(\mathrm{p}<0.0001)$.

Al analizar comparativamente el desarrollo embrionario y fetal del gato con el de otras especies, se aprecia que la extensión del periodo fetal respecto de la duración de la gestación o incubación (en individuos ovíparos u ovovivíparos) varía. Así, en la especie humana representa un $78.9 \%$ del periodo gestacional; en el gato un $54.8 \%$; en la lagartija ovovivípara (Liolaemus tenuis tenuis) un $38.5 \%$ y en el degu (Octodon degus) un $33.3 \%$ (ver Tabla I). Aparentemente, se puede apreciar que existe una relación positiva entre la extensión del periodo fetal y la dependencia materna de las crías (nidícolas y nidífugos). En efecto, los individuos nidífugos presentarían un periodo fetal proporcionalmente más corto, en relación a la duración de la gestación.

ILLANES, J.; ORELlANA, C.; FERTILIO, B.; LEYTON, V. \& VENEGAS, F. Macroscopic and microscopic analysis of the embryonic and fetal growth in the cat (Felis catus), in relation to chorionic vesicle and placental development. Int. J. Morphol., 25(3):467-481, 2007.

SUMMARY: The domestic cat (Felis catus) presents a gestation that lasts $62 \pm 5$ days. However, gestational age determination in a more precise way is difficult, as there are no analysis that correlate chorionic vesicle size; placental development; embryonic and fetal development during gestation. In this work 12 gravid uteruses from hybrid cats between 8 and 18 months of age were studied; these were fixed in $10 \%$ neutral formaldehyde. For each uterus the chorionic vesicles number was determined. The embryos, fetuses and placenta were removed, measured, weighed and photographed for morphologic analysis. The embryonic and fetal stages of development were determined according to the external characteristics and structures of the embryos or fetuses, from gastrulation to term. At 13 days of gestation a late gastrula was observed; between days 13 and 18, somitic embryos; between days 18 and 28, prefetal embryos; and fetuses from day 28 until birth. The amnion is closed by day 17; differentiation of the facial region occurs between days 16 and 28, while limb development takes place between days 17 and 28. At 15 days of gestation the heart begins to beat and the endocardial tube is observed. Septation of the heart occurs between days 17 and 20 and the neural tube is closed by day 17. All parameters studied in the different developmental stages in the cat are significantly correlated $(\mathrm{p}<0.0001)$.

KEY WORDS: Cat; Felis catus; Embriology; Embryonic development; Fetal development. 


\section{REFERENCIAS BIBLIOGRÁFICAS}

Böhme, G. Formation of the central and dorsal glial septum in the spinal cord of the domestic cat. J. Anat., 159:37-47, 1988.

Denker, H.W; Eng, L. A. \& Hamner, C. E. Studies on the early development and implantation in the cat. Anat. Embriol., 154:39-54, 1978.

England, G. C. Vet. Clin. North Am. Small Anim. Pract., 28 (4):849-68, 1998.

Feldmand, E. \& Nelson, R. Canine and feline endocrinolgy and reproduction. $2^{\text {nd }} \mathrm{ed}$. Saunders, Philadelphia, 1996.

Goodrowe, K. L; Howard, J. G. \& Wildt, D. E. Comparison of embryo recovery, embryo quality, oestradiol-17 B and progesterone profiles in domestic cat (Felis catus) at natural or induced oestrus. J. Reprod. Fertil., 82: 553-61, 1988.

Gruffydd-Jones, T. J. Aparato Genital. In: Chandler, E. A.; Gaskell, C. J. \& Hilbery, A. Medicina y terapéutica felina. Ed. Acribia, Zaragoza, 1990. pp. 177-82.

Hamner, C. L; Jennings, L. L. \& Sojka, N. J. Cat (Felis catus) spermatozoa requiere capacitation. J. Reprod. Fertil., 23:477-80, 1970 .

Leiser, R. \& Koob, B. Development and characteristics of placentation in a carnivore, the domestic cat. J. Exp. Zool., 266: 642-56, 1993.

Lemus, D; Illanes, J; Fuenzalida, M; Paz de la Vega, Y. \& García, M. Comparative analysis of the development of the lizard, Liolaemus tenuis tenuis. II. A series of normal postlaying stages in embryonic development. $J$. Morphol. 169:337- 49, 1981.

Lemus, D. \& Duvauchelle, R. Desarrollo intrauterine de Liolaemus tenuis tenuis. Biológica, 39:80-98. 1966.

Melivilu, R. M. Ecografía obstétrica en la gata doméstica. Mevepa, 8 (5):26-31, 1994.

Nelson, N. S. \& Cooper, J. The growing conceptus of the domestic cat. Growth 39: $435-51,1975$.

Nodem, D. \& De Lahunta, A. Embriología de los animales domésticos. Ed. Acribia, Zaragoza, 1990.

Paape, S. R; Shille, V. M; Seto, H. \& Stabenfeldt, G. H. Luteal activity in the pseudopregnacy cat. Biol. Reprod., 13:4704, 1975.
Rojas, M. A.; Montenegro, M. A. \& Morales, B. Embryonic development of the degu, Octodon degus. J. Reprod. Fert. 66:31-8, 1982.

Roth, T. L., Swanson, W. F. \& Wildt, D. E. Developmental competence of domestic cat embryos fertilized in vivo versus in vitro. Biol. Reprod., 51:441-51, 1994.

Sadler, T. W. Embriología Médica de Langman. 9ª ed. 2004.

Serpell, S. A. The domestication of the cat. In: D.C. Turner and P. Bateson (eds). The domestic cat: The biology of its behaviour. Cambridge University press. Cambridge, 1988. pp. $151-8$

Sojka, N. J.; Jennings, L. L. \& Hamner, C. E. Artificial insemination in the cat. Lab. Anim. Care, 20:198-204, 1970.

Swanson, W. F; Roth, T. L. \& Wildt, D.E. In vivo embryogenesis, embryo migration, and embryonic mortality in the domestic cat. Biol. Reprod., 51: 452-64, 1994.

Thatcher, M. J. D; Shille, V. M; Fliss, M. F; Bazer, F. W; Sisum, W. \& Randal, S. Characterization of feline conceptus proteins during pregnancy. Biol. Reprod., 44:108-20, 1991.

Vatti, G. Ginecología y obstetricia veterinaria. Grupo Noriega (eds.). México. 1992.

Verstegen, J. P; Silva, L. D; Onclin, K. \& Donna, I. Echocardiographic study of heart rate in dog and cat fetuses in utero. J. Reprod. Fertil. Suppl. 47:175-80, 1993.

Wildt, D. E.; Seager, S. W. J. \& Chakraborty, P. K. Effect of copulatory stimuli on incidence of ovulation and on serum luteinizing hormone in the cat. Endocrinology, 107(4):121226, 1980 .

Yurac, C. \& Pereda, J. Correlación embriológico-ecográfico del primer trimestre de la gestación. Rev. Chil. Obstetricia y Ginecol., 59 (5):346-58, 1984.

Dirección para Correspondencia:

Prof. Dr. Julio Illanes Herrero

Departamento de Morfología,

Facultad de Medicina, Clínica Alemana

Universidad del Desarrollo

Av. Las Condes 12.438, Lo Barnechea.

Santiago-CHILE

Email: jillanes@udd.cl

Recibido : 20-03-2007

Aceptado: 26-04-2007 
